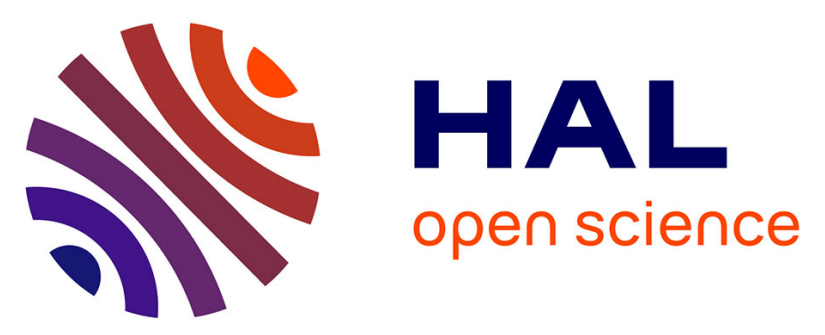

\title{
Nature, predictor, and outcomes of motivation trajectories during a professional training program
}

Emilie Sandrin, A.J.S. Morin, C. Fernet, Tiphaine Huyghebaert-Zouaghi, M.

Suarez, F. Duarte, Nicolas Gillet

\section{- To cite this version:}

Emilie Sandrin, A.J.S. Morin, C. Fernet, Tiphaine Huyghebaert-Zouaghi, M. Suarez, et al.. Nature, predictor, and outcomes of motivation trajectories during a professional training program. European Journal of Work and Organizational Psychology, 2022, 31, pp.226-244. 10.1080/1359432X.2021.1950140 . hal-03280263

HAL Id: hal-03280263

https://hal-univ-tours.archives-ouvertes.fr/hal-03280263

Submitted on 19 Aug 2021

HAL is a multi-disciplinary open access archive for the deposit and dissemination of scientific research documents, whether they are published or not. The documents may come from teaching and research institutions in France or abroad, or from public or private research centers.
L'archive ouverte pluridisciplinaire $\mathbf{H A L}$, est destinée au dépôt et à la diffusion de documents scientifiques de niveau recherche, publiés ou non, émanant des établissements d'enseignement et de recherche français ou étrangers, des laboratoires publics ou privés. 
Running Head: Motivation Trajectories

Nature, Predictor, and Outcomes of Motivation Trajectories during a Professional Training Program

Émilie Sandrin*, Université de Tours, QualiPsy EE 1901, Tours, France

Alexandre J.S. Morin*, Substantive Methodological Synergy Research Laboratory, Department of Psychology, Concordia University, Montreal, Canada

Claude Fernet, Laboratoire de Recherche Interdisciplinaire sur les Processus Motivationnels,

Département de gestion des ressources humaines, Université du Québec à Trois-Rivières, Trois-

Rivières, Canada

Tiphaine Huyghebaert-Zouaghi, Université de Reims Champagne-Ardenne, Cognition Santé Société EA 6291, Reims, France

Morgane Suarez, Via-Ethys, Tours, France

Franck Duarte, Via-Ethys, Tours, France

Nicolas Gillet, Université de Tours, QualiPsy EE 1901, Tours, France

Institut Universitaire de France (IUF)

* The first two authors (E.S. \& A.J.S.M.) contributed equally to this article and their order was determined at random: Both should thus be considered first authors.

Corresponding author

Nicolas Gillet,

Université de Tours,

UFR Arts et Sciences Humaines,

Département de psychologie,

3 rue des Tanneurs, 37041 Tours Cedex 1, France

E-mail: nicolas.gillet@univ-tours.fr

This is the prepublication version of the following manuscript:

Sandrin, E., Morin, A. J. S, Fernet, C., Huyghebaert-Zouaghi, T., Suarez, M., Duarte, F., \& Gillet, N. (in press). Nature, predictor, and outcomes of motivation trajectories during a professional training program. European Journal of Work and Organizational Psychology. Early view. https://doi.org/10.1080/1359432X.2021.1950140

(C) 2021. This paper is not the copy of record and may not exactly replicate the authoritative document published in European Journal of Work and Organizational Psychology. 


\begin{abstract}
Trainees' motivation is an important factor to consider in order to strengthen their learning, wellbeing, and involvement in training sessions. Unfortunately, prior research has often adopted a static (cross-sectional) and unidimensional perspective of training motivation, been limited by the consideration of a very limited range of outcomes, and failed to consider the possible predictors of trainees' motivation. To address these limitations, the present study examines the shape, determinants (autonomy-supportive behaviors), and outcomes (positive and negative affect, fatigue, engagement, learning, and satisfaction) of autonomous and controlled motivation trajectories over the course of a professional training program. A sample of 43 employees completed the measures on four occasions (first day, three weeks, 10 weeks, and 14 weeks) over the course of a 14-week professional training program. This study also relies on a burst design, whereby employees completed each measure twice (with a half-day interval) at each measurement occasion to achieve a more accurate representation of occasion-specific ratings. Results from three-level growth analyses (with the two bursts at Level 1, four occasions at Level 2, and participants at Level 3) showed that autonomous motivation, negative affect, learning, and satisfaction appeared to follow curvilinear trajectories, whereas autonomy support and positive affect followed linear trajectories. In contrast, controlled motivation, fatigue, and engagement levels remained stable over time, consistent with an intercept-only model. Furthermore, higher levels of autonomy support were associated with higher levels of autonomous motivation, and lower levels of controlled motivation over time. Finally, higher initial levels of autonomous motivation predicted higher levels of positive affect, learning, satisfaction, and engagement, and lower levels of fatigue over time, whereas higher initial levels of controlled motivation predicted higher levels of fatigue over time.
\end{abstract}

Keywords: Motivation trajectories; self-determination theory; professional training; autonomysupportive behaviors; affect; engagement; satisfaction; fatigue; learning. 
Employee training and development is a widespread human resource practice aiming to improve individual, team, and organizational effectiveness (Sung \& Choi, 2014). In 2017, US organizations spent $\$ 90.6$ billion and an average of 47.6 hours per employee on professional development and training (Training Magazine, 2017). With the multiple changes that have characterized the workplace over the past decades (globalization, information availability, frequent job transitions, remote work, etc.), both research and practice on professional training shifted from a focus on the trainers to a focus on the trainees themselves (Kraiger \& Ford, 2007). Thus, "to grasp more fully what actually goes on during training, we need to consider the more active role of employees during training" (Dysvik \& Kuvaas, 2014, p. 219), and more specifically training motivation (Noe et al., 2010). Training motivation is traditionally defined as the direction, intensity, and persistence of trainees' behaviors (Colquitt et al., 2000). Research has previously shown that training motivation to be associated with a variety of positive outcomes including higher levels of affective commitment to the organization, lower levels of training skepticism, and lower levels of cynicism toward change (Walsh \& Magley, 2020). Likewise, training motivation has also been found to be associated with higher levels of organizational identification and with higher levels of intentions to adopt training- related organizational citizenship behaviors (Rawski \& Conroy, 2020). These effects seem to occur, notably, as a result of the higher level of proactivity displayed by highly motivated trainees during the training sessions (e.g., taking action to change their environment, focusing on self-development, behaving more confidently, setting high standards, seeking out information; Roberts et al., 2018).

However, training motivation may be caused by different reasons (e.g., pleasure, shame, rewards). Because self-determination theory (SDT; Ryan \& Deci, 2017) does not propose a unitary conceptualization of motivation but rather integrates two broadly differentiated types of motivation (e.g., autonomous and controlled motivations), this framework appears to be well suited to increase our understanding of trainees' motivation. More specifically, trainees' behavioral regulations may be both autonomous (i.e., trainees are inherently motivated to develop their interests and skills) and controlled (i.e., trainees' behaviors are motivated by external and/or internal pressures). In addition, these two types of motivation have different implications for training outcomes. Indeed, numerous studies have shown that autonomously motivated trainees, compared to trainees mainly driven by 
controlled motivation, are more likely to react more positively to the training, perceive the training material more constructively, and demonstrate higher levels of persistence in acquiring training content (see Ryan \& Deci, 2017).

Importantly, although motivation is considered to be a dynamic process (Ryan \& Deci, 2017; Vallerand, 1997), only a handful of studies have adopted a dynamic perspective for the study of training motivation trajectories. Thus, a major contribution of this study lies in the adoption of an intensive longitudinal design, allowing us to clarify how autonomous and controlled motivations evolve over the course of a 14-week professional training program, and examining their determinants (i.e., autonomy-supportive behaviors) and outcomes (i.e., positive and negative affect, engagement, satisfaction, fatigue, and learning). This is likely to help improve our understanding of the psychological mechanisms at play during training and to lead to more focused intervention strategies by providing clarity regarding which specific factors can be leveraged to strengthen trainees' optimal functioning. For instance, based on the present findings, we might suggest interventions aiming to enhance trainees' autonomous motivation (e.g., by encouraging trainers' autonomy-supportive behaviors) in order to facilitate their adoption of a more active role, their learning, and their well-being during the training sessions. More generally, through the adoption of this dynamic approach to research on training motivation, it may become possible for training interventions to be better timed, thus contributing to substantially enhancing their efficacy (Greenberg et al., 2003).

To better understand the dynamic role played by trainees' motivation trajectories, we focus on a broad range of outcomes known to play a role in influencing the success (in terms of learning and training transfer) of professional training programs: Positive and negative affect, fatigue, engagement, learning, and satisfaction. Positive affect, contrary to negative affect who is generally found to have opposite effects, has been shown to facilitate learning, transfer, and work performance by positively influencing behavioral, motivational, physical, and/or cognitive functioning (Fredrickson, 2014; Gillet et al., 2013d). We also assessed trainees' engagement, which is known to be strongly and positively associated with training transfer intentions and perceptions of training utility (Rangel et al., 2015). Importantly, prior studies also demonstrated that highly engaged trainees tend to present higher levels of training satisfaction (Gillet et al., 2015b), which operates as another important predictor of training 
transfer (Grossman \& Salas, 2011).

In contrast, fatigue reflects the reduction of one's functional capacity due to extreme tiredness (Frone \& Tidwell, 2015) and has long been recognized as a precursor of a wide variety of undesirable outcomes for organizations (e.g., higher levels of dropout and turnover intentions; Cai et al., 2018) and employees (e.g., lower sleep quality and quantity; Frone \& Blais, 2019; cognitive impairments and reduced performance: Belenky et al., 2003). Finally, we also assess trainees' perceptions of having learned something as part of the training program based on prior results supporting the major role played by this variable in training transfer and performance (Hart et al., 2019) as well as in dropout and turnover (van der Vegt et al., 2010).

\section{Self-Determination Theory}

SDT (Ryan \& Deci, 2017) posits that trainees can be motivated for various reasons. On the one hand, motivation can be considered to be autonomous, reflecting a volitional engagement in activities (such as a professional training program) that are seen as inherently interesting and pleasurable (i.e,, intrinsic motivation) or that serve a personally-endorsed value or objective (i.e., identified regulation). On the other hand, motivation can be considered to be controlled by internal (e.g., avoiding of shame and guilt, or seeking pride or self-aggrandizement: Introjected regulation) or external (e.g., punishments, constraints, or rewards: External regulation) contingencies. Past research has supported the distinct nature of these types of motivation proposed by SDT and their organization according to autonomous or controlled dimensions (Delrue et al., 2016; Gagné et al., 2015), as well as their different effects on training outcomes (Deci et al., 2017; Gagné \& Deci, 2005). More precisely, autonomous motivation is generally found to be associated with higher levels of performance, more positive psychological functioning, and fewer undesirable outcomes such as negative affect, fatigue, or dropout intentions (e.g., Fernet et al., 2017; Gillet et al., 2010; Howard et al., 2016; Sandrin et al., 2019). In contrast, controlled motivation presents the opposite relations with these outcome variables (e.g., Fernet et al., 2020a; Gillet et al., 2013a, 2016; Howard et al., 2016). Overall, research has thus tended to support SDT propositions regarding the greater desirability of autonomous forms of motivation, and the undesirability of a training approach mainly driven by controlled forms of motivation.

\section{A Longitudinal Perspective of Motivation during Professional Training}




\section{Empirical Evidence}

The bulk of research on motivation conducted within training, work or educative contexts has relied on cross-sectional designs, or on longitudinal designs involving only two measurement occasions (e.g., Gillet et al., 2013b, 2017b) precluding the analysis of motivation trajectories as they evolve over time (Ployhart \& Vandenberg, 2010). To inform this issue, more intensive longitudinal investigations (i.e., including three or more measurement occasions) are necessary.

When seeking to better grasp the longitudinal dynamics of motivation, a first source of longitudinal evidence comes from the examination of rank-order stability. For instance, in an eight-month longitudinal study of 196 temporary agency workers, Lopes and Chambel (2017) obtained results supporting the idea that autonomous and controlled motivations were mainly situational and thus presented only a moderate level of rank-order stability $(r=.51$ to .55 ; also see Fernet et al., 2012, for similar results). A second source of evidence, for the moment limited to educational studies of primary and secondary students, comes from the examination of longitudinal trajectories of motivation. Generally, these studies reveal slightly decreasing trajectories of autonomous motivation and slightly increasing trajectories of controlled motivation as students become older (e.g., Leroy \& Bressoux, 2016; Maulana et al., 2013). One more recent study (Gillet et al., 2018a) of upcoming police officers undergoing vocational training revealed that three profiles best represented trainees' motivational trajectories over a period of 41 weeks: (a) one displaying high initial levels of autonomous motivation and a slight increasing tendency; (b) one displaying moderate initial levels of autonomous motivation and a very slight decreasing tendency; and (c) one displaying low initial levels of autonomous motivation and a slight decreasing tendency.

Despite their interest, these prior studies present some noteworthy limitations, at least from the perspective of the present study. One of those limitations comes from the lack of research specifically focused on the professional training context. In this regard, only Gillet et al. (2018a) specifically focused on individuals enrolled in a vocational training program. However, even then, participants can still be considered to be students training to start their work as police officers. As such, no direct information is available regarding the evolution of motivation trajectories as they unfold in real time as part of a professional training experience. Yet, it is important to consider these motivation 
trajectories during training to understand trainees' functioning (e.g., dropout intentions, difficulties in learning; see Vallerand, 1997). A second intimately-related limitation stems from the dearth of research evidence concerning the characteristics of the training context involved in supporting autonomous motivation and limiting controlled motivation. In this regard, Gillet et al. (2018a) did document the role of demands and resources linked to the training context (peer support, work load, emotional load, and mental load; similar work characteristics were also studied by Fernet et al., 2020a). However, it would be even more informative for purposes of intervention to focus on drivers falling more directly under the control of the trainers, such as their autonomy-supportive behaviors (Deci et al., 1989), which are a focal point of the present study. Indeed, SDT (Ryan \& Deci, 2017) emphasizes the central role of trainees' perceptions of being exposed to autonomy-supportive behaviors from their trainer (Deci et al., 1989).

Third, although we have theoretical reasons (Deci et al., 2017; Ryan \& Deci, 2017) to expect autonomous and controlled motivations to play a role in influencing trainees' psychological functioning, involvement, and learning as part of their training programs, evidence in this specific context is lacking. Once again, Gillet et al. (2018a) provided indirect evidence by showing that motivation trajectories influenced trainees' positive affect, negative affect, and performance, and Fernet et al. (2020a) documented the role of motivational profiles in relation to workers' emotional exhaustion, performance, and intentions to leave their organization and occupation. The present study expands on these previous studies by considering a broader range of outcomes (positive and negative affect, fatigue, engagement, learning, and satisfaction) having a strong influence on the success of professional training programs (Grossman \& Salas, 2011; Hart et al., 2019).

\section{Theoretical Considerations}

The relative dearth of research focusing specifically on motivational trajectories is critical when considering motivation, which is defined by SDT as a partly situational construct (Gillet et al., 2010, 2013c). More precisely, although both stable individual factors and environmental contingencies are known to play a role in influencing motivation, situational factors (such as autonomy-supportive behaviors displayed by trainers) are assumed to play an even greater role (Vallerand, 1997). Beier and Kanfer's (2009) phase perspective on motivation in training contexts explicitly assumes that 
motivation will fluctuate during training in a way that sometimes drastically differs from one trainee to another. Indeed, despite the generally voluntary and desired nature of enrollment in a specific training program, integration into this new program is unlikely to be automatic or instantaneous, and to unfold in the same manner for all trainees. In addition, the predictor (i.e., trainer's autonomy-supportive behaviors) and outcomes (positive and negative affect, fatigue, engagement, learning, and satisfaction) assessed in the present study also present a strong situational component (e.g., Cheon et al., 2019; Gillet et al., 2019; Huyghebaert et al., 2018b; Mageau et al., 2017; Sadikaj et al., 2015), making them naturally suited for an investigation of their dynamic associations with motivation trajectories.

Theoretical perspectives focusing on how individuals are socialized to a new environment suggest that stability and change in trainees' autonomous and controlled motivation trajectories are likely to be influenced right from the start of their training program (Fernet et al., 2020b) depending on whether this early exposure to the training context meets or falls short of trainees' expectations (e.g., Solinger et al., 2013; Weiss, 1978). Indeed, integration starts to occur when trainees perceive that their training environment matches their own goals and values (O'Reilly et al., 1991), leading to increases in autonomous motivation over time as they progressively come to endorse and internalize the objectives and contents of the training program to their identity (Deci \& Ryan, 2000; Fernet et al., 2020b). Then, as training progresses, motivational trajectories might be further influenced by the nature of their training experiences (Ryan \& Deci, 2017), so that increases in trainees' autonomous motivation trajectories might occur when trainees experience higher levels of autonomy and flexibility (Gillet et al., 2012b), become exposed to tasks that are more personally meaningful and interesting (Dysvik \& Kuvaas, 2014), and start to feel increasingly competent (Wigfield \& Eccles, 2000) over the course of the training.

In contrast, when trainees are exposed, initially or over time, to a training environment not fully aligned with their own goals and values, socialization and integration may be delayed or blocked, leading to increases in controlled motivation due to trainees' inability to internalize the goals and content of the program (Deci \& Ryan, 2000). This situation can occur for many reasons, such as exposure to a training context failing to expose trainees to sufficient levels of autonomy and control, and focusing on contents that fail to meet trainees' expectations and to stimulate their interest, or that 
fail to generate an increased sense of competence (e.g., Dysvik \& Kuvaas, 2014; Gillet et al., 2012b;

Wigfield \& Eccles, 2000), thus forcing trainees to be motivated by internal and/or external pressures. In addition, the assessment procedures typically implemented at the end of professional training programs also tend to be perceived as controlling, externally-driven, and stressful by participants, leading to further increases in controlled motivation (Dysvik \& Kuvaas, 2014).

Based on this theoretical rationale and considering the limited empirical evidence currently available, we propose the following hypothesis:

Hypothesis 1. On the average, trainees' autonomous and controlled motivation trajectories will display a slight increasing tendency over time.

\section{Trainer Autonomy Support as a Determinant of Motivation Trajectories}

To better understand the mechanisms via which trainers can influence trainees' motivation, we specifically focus on the role of trainees' perceptions of trainer autonomy support over the course of the training program. Trainers who adopt autonomy-supportive behaviors provide trainees with critical information about their role, do not use control to motivate them, acknowledge their feelings in an empathic manner (Black \& Deci, 2000), and are thus expected to help nurture autonomous motivation over the course of the training. Exposure to autonomy-supportive behaviors also facilitates the satisfaction of the psychological needs for autonomy, competence, and relatedness, and limit the frustration of these needs (Deci et al., 2017). As a result, trainees exposed to autonomy-supportive behaviors should be more likely to value their training context, and to invest efforts into their training activities for autonomous reasons rather than for controlled ones (Ryan \& Deci, 2017).

However, despite the central importance played by autonomy-supportive behaviors in SDT, we are not aware of any study in which the effects of this variable on trainees' autonomous and controlled motivation trajectories has been investigated. Nevertheless, numerous investigations have shown that individuals' perceptions of autonomy-supportive behaviors from their teachers (Gillet et al., 2012a b; for a review, see Núñez \& León, 2015) or work supervisors (Gillet et al., 2013a; for a meta-analysis, see Slemp et al., 2018) predicted increases in autonomous motivation and decreases in controlled motivation.

In addition, prior longitudinal studies conducted in the educational and work domains have shown 
that individuals' perceptions of autonomy support from their teachers or supervisors fluctuate over time. For instance, when considering rank-order stability, research shows results consistent with a moderate level of stability ( $r=.50$ to .70 over periods of one year of less) and decreases over time ( $r=$ .20 to .40 over periods longer than one year), consistent with the presence of situational influences on autonomy-supportive behaviors (e.g., Diseth et al., 2018; Jang et al., 2012; Olafsen, 2017). Likewise, longitudinal studies generally suggest that autonomy-supportive teaching practices tend to increase over time (e.g., Cheon \& Reeve, 2015; Langdon et al., 2017; Reeve \& Cheon, 2016; Zhang et al., 2020). These increases are consistent with the idea that, over time, trainers may be able to nurture training contexts that become increasingly autonomy-supportive over time as mastery of the basic skills covered earlier in the program allows them to better connect with the trainees' interests and preoccupations (Dysvik \& Kuvaas, 2014).

In terms of differences in initial levels of autonomy-supportive behaviors, trainers begin any professional training program with a personal history that might make them more or less autonomysupportive. Some trainers might be more autonomy-supportive based on their own individual characteristics and experiences (Reeve et al., 2018), because they have been able to benefit from the experience gained form previous training sessions (Rocchi \& Pelletier, 2017), and because they might be more or less motivated to learn from these previous experiences (Day \& Sin, 2011).

Importantly, trainers' autonomy-supportive behaviors may evolve over the course of the training program as a function of their interactions with the trainees and of their early experiences of success or failure (Moshman, 2003). When beginning a training program, trainees are unfamiliar with many aspects of the program and thus tend to look for information to help them reduce uncertainty and better understand their new environment. These early interactions with the trainees may strengthen the salience and centrality of trainers' identity, especially when they perceive these interactions in a positive manner (Day et al., 2009). When autonomy support is experienced in a positive way (e.g., trainees commit enthusiastically to a proposed task and accept trainers' attempts at influencing them), trainers' self-efficacy increases and trainers become increasingly motivated to adopt such behaviors over time (Day \& Sin, 2011; DeRue \& Ashford, 2010). Moreover, according to the selectionoptimization-compensation meta-model (Baltes, 1997; Freund \& Baltes, 2002), trainers' autonomy- 
supportive behaviors may increase over the course of a professional training program because they are able to select appropriate goals from alternative possibilities, allocate and refine internal of external resources (e.g., effort, time) as a means of achieving an optimal functioning during training, and compensate and adapt when their goal striving is thwarted.

Moreover, it is possible that the increases in trainees' learning and performance traditionally observed over the course of a training program may lead trainers to be more autonomy-supportive as they feel they do not need to use directive language and be critical of the trainees (Barrow, 1976). Trainers' may also adopt more autonomy-supportive behaviors because their beliefs about trainees' autonomous motivation increase (Pelletier \& Vallerand, 1996). Indeed, trainers use preconceived expectations and beliefs about trainees to determine their interpersonal behaviors (Snyder, 1992). Yet, as previously hypothesized, trainees' autonomous motivation may increase during the training program (Gillet et al., 2018a), in turn leading to higher levels of trainers' autonomy support because they feel competent and liked by the trainees (Skinner \& Belmont, 1993). More generally, this process should follow several steps: (a) trainers adopt particular beliefs about trainees (e.g., high expectations concerning trainees' competence); (b) trainers treat the trainees differently according to these expectations (e.g., more autonomy-supportive behaviors), (c) trainees' behaviors confirm the trainers' initial expectancies (e.g., trainees perceiving higher levels of autonomy support are more likely to be performant), and (d) the trainers' original expectations are reinforced and the process continues (Snyder, 1992). Pelletier et al. (2002) also demonstrated that the effects of trainees' motivation on trainers' behaviors were not direct but mediated by trainers' motivation. More specifically, the more trainers perceived trainees to be autonomously motivated, the more they displayed high levels of autonomous motivation. In turn, this increase in autonomous motivation was associated with higher levels of autonomy-supportive behaviors.

These various considerations lead us to propose the following hypotheses:

Hypothesis 2. On the average, trainees' perceptions of autonomy-supportive behaviors from their trainer will display a slightly increasing trajectory over time.

Hypothesis 3. Trainees' perceptions of autonomy-supportive behaviors from their trainer will predict higher initial levels of autonomous motivation, and increases over time in these levels. 
Hypothesis 4. Trainees' perceptions of autonomy-supportive behaviors from their trainer will predict lower initial levels of controlled motivation, and decreases over time in these levels.

\section{Outcomes of the Motivation Trajectories}

Although research has seldom investigated the training outcomes considered in the present research (positive and negative affect, fatigue, engagement, learning, and satisfaction) in direct relation to trainees' motivation (apart from Gillet et al., 2018a who demonstrated associations between motivation trajectories and trainees' levels of positive and negative affect), the bulk of research conducted in the educational and work areas has generally supported SDT expectations (Ryan \& Deci, 2017). More precisely, current research evidence supports the idea that autonomous motivation tends to be associated with more desirable levels on these various outcomes, whereas controlled motivation predicts less desirable levels (e.g., Fernet et al., 2017, 2020a; Gillet et al., 2013a, 2016; Howard et al., 2016; Sandrin et al., 2019). Indeed, trainees with high levels of controlled motivation might want to gain attention from others via the expression of negative emotions during the training program (Guay et al., 2020). In addition, their lack of interest and volition in relation to the training content might lead them to not listen to trainers, to miss some courses, and to not engage in several training tasks (Dysvik \& Kuvaas, 2014), thereby limiting their engagement, learning, and satisfaction. In contrast, when trainees are autonomously motivated, they perceive their training program as more agreeable and stimulating and take pleasure during training, allowing them to better sustain continuous efforts, which in turn should allow them to experience more adaptive outcomes (Gillet et al., 2020).

Following from these considerations, we propose the following hypotheses regarding the expected relations between the motivation trajectories and the outcomes. However, lacking systematic evidence regarding the evolution of each of these outcomes over time, we leave as an open question the shape which will best characterize their longitudinal trajectories.

Hypothesis 5. Trainees' autonomous motivation will predict higher initial levels of positive affect, engagement, learning, and satisfaction, and increases over time in levels, as well as lower initial levels of negative affect and fatigue, and decreases over time in these levels.

Hypothesis 6. Trainees' controlled motivation will predict lower initial levels of positive affect, engagement, learning, and satisfaction, and decreases over time in levels, as well as higher initial 
levels of negative affect and fatigue, and increases over time in these levels.

\section{Method}

\section{Sample and Procedure}

This study relies on a sample of 43 participants (Mean age $=45.05 ; S D=9.17 ; 55.8 \%$ male), recruited in France, and undergoing a 14-week professional training program to develop focus group facilitator skills as part of a more global process occurring in their workplace and seeking to promote psychological health at work through the improvement of working conditions. Prior research has already demonstrated that trainees' motivation and trainers' behaviors were likely to evolve and fluctuate over such a short period of time (Day \& Sin, 2011; Jungert et al., 2018). The first day of training (week 1) was mainly theoretical in nature, and was designed to expose the trainees to theoretical and legal knowledge related to psychological health at work in France, its main drivers, and its main consequences. This day was also used to present the focus group methodology that they would have to implement in their workplace, in order to harmonize the practices of all future facilitators (i.e., method, sequence, topics, etc.). The second day of training (week 3) involved role playing methods designed to allow trainees to implement the focus group methodologies presented on the first day, to experience various challenges likely to occur in real life settings, and to benefit from the trainees' help in finding appropriate solutions to these situations. During the third day of training (week 10), the trainers assisted to the first real life focus group conducted by various dyads of trainees. Finally, the first part of the last day (week 14) was designed to provide feedback to all trainees on this first experience and to address the main challenges (and their solutions) that were experienced during these focus groups. The last part of this fourth day of training day more specifically focused on the methods to use to pull together the results from the various focus group into an integrated synthesis in which the identified challenges related to psychological health at work could be highlighted together with their solutions in order to lead to an actionable intervention plan.

Participants took part in the training voluntary and came from a variety of occupational groups (administrative, technical, firefighters, etc.) but worked in the same organization, namely a departmental fire service. They had an average tenure in their position of 6.85 years $(S D=5.18)$. One participant (2.3\%) had no previous diploma, 11 had a vocational training certificate (25.6\%), eight 
already had a previous high school diploma (18.6\%), and 23 already had a previous university diploma (53.5\%). Finally, $74.4 \%$ of the participants worked full-time and $54.8 \%$ held a managerial position.

Participation was voluntary and all participants enrolled in this program were invited to complete a self-report questionnaire at the beginning of the training period (occasion 1: $N=43$ ), and then three (occasion 2: $n=31$ ), ten (occasion 3: $n=16$ ), and fourteen (occasion 4: $n=38$ ) weeks later. Data collection followed a burst design (Rast et al., 2012; Sliwinski, 2008; Stawski et al., 2015) whereby participants had to complete two testing periods (hereafter referred to as bursts) separated by a halfday period at each of the four occasions of measurement. This approach was implemented to increase the reliability of occasion-specific ratings by anchoring them into two distinct measurement bursts (Sliwinski, 2008; see analytic section for additional details), while also accounting for the inherent instability of human behavior (Nesselroade, 1991), allowing us to achieve occasion-specific ratings representative of participants' perceptions over a full day of training. The 43 participants (Level 3) provided a total of 130 occasion-specific ratings (Level 2) and 255 burst-specific ratings (Level 1). At each data collection point, members of the research team explained the purpose of the study to the participants who, after proving informed consent, proceeded to complete a 15-minute questionnaire in the training room. Participants were ensured that their responses would be kept confidential and would not impact their training. They were also asked to provide a personal identification code to allow researchers to match their responses over time.

\section{Measures}

Most of the measures used in this study were already validated in French (i.e., motivation, affect, fatigue, learning, satisfaction). Measures not already validated in French (i.e., autonomy support and engagement) were adapted from the original English version using a translation back-translation procedure realized by independent bilingual experts. Discrepancies were resolved by consensus.

Motivation. We relied on two two-item subscales previously developed in French by Gillet et al. (2014) to assess participants' autonomous (i.e., "Because of the fun and enjoyment that this training provides me", intrinsic motivation; and "Because I really believe that engaging in this training is an important goal to have", identified regulation; $\alpha=.66$ ) and controlled (i.e., "Because I would feel ashamed, guilty, or anxious if I did engage in this training", introjected regulation; "Because 
somebody else wants me to engage in this training or because the situation demands it", external regulation; $\alpha=.67)^{1}$ motivations toward the training at all occasions. Items were rated using a sevenpoint scale ranging from 1 (does not correspond at all) to 7 (corresponds exactly).

Autonomy Support (Predictor). Participants' perceptions of autonomy support from their trainer were assessed at occasions 1, 2, and 4 using a six-item (e.g., "My trainer conveys confidence in my ability to do well in this training"; $\alpha=.90$ ) measure (Jang et al., 2016). Responses were provided using a Likert scale ranging from 1 (disagree) to 5 (agree).

Affect (Outcome). Affect was assessed at all occasions using the short version of the Positive and Negative Affect Schedule (Thompson, 2007; French version by Gillet et al., 2015a). This questionnaire includes two five-item subscales covering negative (e.g., "upset"; $\alpha=.67$ ) and positive (e.g., "active"; $\alpha=.70$ ) affect experienced during the training session. Responses were provided using a five-point scale ranging from 1 (not at all) to 5 (extremely).

Fatigue (Outcome). Participant's levels of mental (six items; e.g., "Actually, I want to mentally shut down"; $\alpha=.94$ ) and emotional (six items; e.g., "Actually, I want to avoid anything that took too much emotional energy"; $\alpha=.95$ ) fatigue were measured at all occasions using the Work Fatigue Inventory (Frone \& Tidwell, 2015; French version by Blais et al., 2020). Following Barling and Frone (2017), we rely on a global score of fatigue $(\alpha=.96)$. The time frame mentioned in the instructions was changed from the past 12 months to the actual situation (Actually...) to assess fatigue at the time of data completion. Items were rated on a five-point scale ranging from 1 (disagree) to 5 (agree).

Learning (Outcome). Learning during the training session was assessed at all occasions using one item (i.e., "How would you rate your overall learning during this training session") from the World Health Organization Health and Work Performance Questionnaire (Kessler et al., 2003; French version by Gillet et al., 2018b). Responses were provided using a scale ranging from 0 (worst

\footnotetext{
${ }^{1}$ Although the estimates of scale sore reliability $(\alpha)$ obtained for these two subscales are located at the lower bound of acceptability, it is important to keep in mind that $\alpha$ coefficients are drastically impacted by the number of items included in a subscale (Streiner, 2003). Indeed, in the present study, the Spearman-Brown prophecy formula (Nunnally \& Bernstein, 1994) indicates that these $\alpha$ would be of .853 (autonomous motivation) and .859 (controlled motivation) if they were based on six items equivalent to the two items included in this study. However, this lower level of reliability also highlights the importance of adopting an approach providing some additional control for unreliability, such as the latent aggregation approach discussed in the analysis section.
} 
learning) to 10 (best learning).

Satisfaction (Outcome). Satisfaction toward the training session was assessed at all occasions using a one-item measure (Shimazu et al., 2015; i.e., “Are you satisfied with this training session?”; French version by Fouquereau et al., 2019). Responses were provided using a scale ranging from 1 (dissatisfied) to 4 (satisfied).

Engagement (Outcome). Engagement in the training session was assessed at occasions 1 and 4 using a questionnaire covering four dimensions (Jang et al., 2016): Behavioral (five items; e.g., "I pay attention in this training session"; $\alpha=.92$ ), emotional (five items; e.g., "When we work on something in this training session, I get involved"; $\alpha=.88$ ), agentic (five items; e.g., "When I need something in this training session, I will ask the trainer for it"; $\alpha=.90$ ), and cognitive (four items; e.g., "When learning about a new topic in this training session, I usually try to summarize it in my own words"; $\alpha=$ .86) engagement. Following Cheon et al. (2019), we rely on a global score of engagement $(\alpha=.95)$. Responses were provided using a Likert scale ranging from 1 (disagree) to 5 (agree).

\section{Analyses}

Analyses were conducted using the Maximum Likelihood Robust (MLR) estimator available in Mplus 8.4 (Muthén \& Muthén, 2019), which is robust to non-normality and to the multilevel structure of the data. Full Information Maximum Likelihood (FIML; Enders, 2010) procedures were used to handle missing data. We relied on three-level multilevel analyses, where measurement bursts were modelled at Level 1, measurement occasions at Level 2, and participants at Level 3. Level 1 was used to account for the presence of two measurement bursts per occasion, using latent aggregation procedures (Marsh et al., 2012; Morin et al., 2014; also referred to as latent variable centering procedures: Asparouhov \& Muthén, 2019) to achieve more reliable occasion specific assessments of the repeated measures reflecting the variance shared among the two bursts net of the variance uniquely associated with each burst (which includes random measurement errors). Levels 2 and 3 were used to specify a multilevel growth model (Hox, 2010; Raudenbush \& Bryk, 2002) in which time of observation (coded in months as 0 for occasion 1, .75 for occasion 2, 2.5 for occasion 3 , and 3.5 for occasion 4) was used as a predictor of the repeated measures, using a random specification to estimate intercepts and slopes of person-specific growth trajectories at Level 3. 
First, we estimated a series of alternative unconditional growth models to identify the optimal shape of the longitudinal process underpinning the growth trajectory of each variable. These analyses were conducted separately for each variable to maximize the parsimony of the estimated models in light of the relatively small number of participants $(N=43)$. Three alternative specifications were contrasted. First, we estimated an intercept-only model, in which the person-specific growth process was assumed to reflect stable trajectories unaffected by time and summarized by a single random intercept reflecting the average level of each person on the repeated measures over time. Second, we estimated a linear model, in which the person-specific growth process was assumed to reflect linear trajectories of time summarized by a random intercept reflecting the initial level of each person at the beginning of the study, and linear random slope reflecting person-specific average levels of growth per month over the course of the study. Finally, we estimated a quadratic (curvilinear) model in which a second random slope was added to reflect the possible curvilinear function of time (using time ${ }^{2}$ as a predictor). Traditional goodness-of-fit indices are not available with three-level models involving random slopes. For this reason, these models were contrasted on the basis of an examination of parameter estimates together with the consideration of four information criterion (IC): The Akaike IC (AIC), the Consistent AIC (CAIC), the Bayesian IC (BIC), and the sample-size Adjusted BIC (ABIC). Lower values on these IC suggested a better fitting model.

Once the optimal unconditional representation of each variable longitudinal trajectory was achieved, we combined them via conditional growth models. In these models, longitudinal trajectories of autonomous and controlled motivations were simultaneously taken into account, and allowed to be predicted by autonomy support, or to predict the outcomes (positive affect, negative affect, fatigue, learning, satisfaction, and engagement). These conditional models were estimated while taking into consideration the longitudinal trajectories of a single covariate at a time to maximise parsimony. In these analyses, we considered four alternative specifications, compared to one another using a process similar to that described above for the comparison of the unconditional growth models. First, we estimated a null effect model in which the Level 3 effects of the random intercept and slopes of the predictor variable on the random intercept and slopes of the outcome variable were constrained to be zero. In this model, the effects of the Level 2 occasion-specific deviations of the predictor variable on 
the Level 2 occasion-specific deviations on the outcome variable were also constrained to be zero. Second, we estimated a model in which we allowed the Level 3 associations between the random intercepts of the predictor and outcome variables to be freely estimated, as well as the Level 2 associations between occasion-specific deviations on the predictor and outcome variables. Third, we also allowed Level 3 associations involving the random linear slopes of the predictor and outcome variables to be freely estimated. Fourth, we finally allowed associations involving the random quadratic slopes of the predictor and outcome variables to be freely estimated. Given our interest in growth processes occurring at the individual level, coefficients involving the random intercept and slopes were standardized at the person level.

Before proceeding with the estimation of these models, however, we also conducted a set of preliminary analyses to investigate the relevance of incorporating demographic variables as additional Level 3 predictors of the motivation trajectories in the model designed to investigate the role of autonomy support. The results from this additional model including all demographic covariates is reported in Table S1 of the online supplements and revealed a single statistically significant effect of participants' sex on their initial levels of controlled motivation (consistent with the presence of lower levels of controlled motivation among females). Sex was thus incorporated as an additional Level 3 predictor to the model including autonomy support. Level-specific correlations among all variables are reported in Table $\mathrm{S} 2$ of the online supplements.

\section{Results}

\section{Motivation Trajectories}

The IC associated with the unconditional models are reported in Table 1, whereas parameter estimates from the retained parameterization for each variable are reported in Table 2, together with intraclass correlation coefficients indicating the proportion of variance located at Level 2 (occasion) and 3 (person) for each variable. These intraclass correlation coefficients indicate that between $8.3 \%$ and $90.5 \%$ of the variance occurred at the occasion level, whereas $4.6 \%$ to $66.1 \%$ of the variance occurred at the person level. More precisely, some variables displayed a level of variability that appeared to be evenly spread across occasions and persons (i.e., autonomous motivation, autonomy support, negative affect, and fatigue), whereas other variables varied mainly across occasions (i.e., 
learning and satisfaction) or persons (i.e., controlled motivation, positive affect, and engagement).

For autonomous motivation, two of the indicators (CAIC and BIC) support the intercept-only model, whereas the remaining two indicators (AIC and ABIC) rather support the quadratic model, a result which is further supported by an examination of the parameter estimates associated with each model, which are consistent with the presence of a curvilinear trajectory. The results from this quadratic model are reported in Table 2 , indicating statically significant variability at all three levels, and statistically significant estimates of the mean value and variance estimates associated with all random intercepts and random slopes. To facilitate interpretation of these findings, a graphical representation of the average autonomous motivation trajectory observed in this sample is graphically depicted in Figure 1a, revealing high initial levels of autonomous motivation (5.099 on a 1 to 7 scale) showing moderate growth until reaching an inflection point located 2.35 months after the start of the training, and then showing a slow decrease till the end of the study. In contrast, controlled motivation trajectories seem to match an intercept-only model (as illustrated by lower values of all IC) characterized by relatively low (1.781 on a 1 to 7 scale) average levels remaining stable over time.

When considering the remaining variables, the IC unequivocally support the presence of linear trajectories for autonomy support (the presence of only three measurement occasions precluded the estimation of quadratic trajectories for this variable) and positive affect, and of intercept-only models for fatigue and engagement (the presence of only two measurement occasions precluded the estimation of linear or quadratic trajectories for this variable). Results from these solutions revealed average trajectories characterized by initially high levels of autonomy support (4.114 on a 1 to 5 scale) and positive affect ( 3.599 on a 1 to 5 scale), both characterized by a slow but steady normative with only negligible within person-variability rate of increase over time (.122 per month for autonomy support and .074 per month for positive affect). Likewise, the results revealed the presence of high (4.233 on a 1 to 5 scale) and stable levels of engagement, and of low (1.735 on a 1 to 5 scale) levels of fatigue.

The remaining variables (negative affect, learning, and satisfaction) appeared to follow quadratic trajectories according to all IC for learning and satisfaction, and to the AIC and ABIC for negative affect (coupled with an examination of parameter estimates). These average quadratic trajectories are respectively illustrated in Figures $1 \mathrm{~b}, 1 \mathrm{c}$, and 1d. For negative affect, the results revealed an average 
trajectory characterized by initially low levels (1.384 on a 1 to 5 scale) showing a small increase until reaching an inflection point 1.39 month after the beginning of the training, followed by a small but steady decrease until the end of the study. For learning, the results revealed initially moderately high average levels ( 7.307 on a 0 to 10 scale) followed by steep increases until reaching an inflection point 1.73 month after the beginning of the training, followed by a decreasing trajectory till the end of the study. Finally, average satisfaction trajectories were characterized by initially high levels (3.316 on a 1 to 4 scale) displaying a slight decrease early on in the training program, followed by marked increases starting 1.02 month after the beginning of the training.

\section{Predictors}

The IC associated with the conditional models are reported in Table 3. Regarding the predictive role of autonomy support trajectories on participants' motivation trajectories, the AIC, ABIC, and an examination of the parameter estimates associated with the alternative models support the presence of associations limited to the intercept of the various trajectories. The parameter estimates from this solution are reported in Table 3. These results first indicate a lack of associations at the occasion level between autonomy support perceptions and motivation, showing that occasion-specific fluctuations in autonomy support perceptions did not predict occasion-specific fluctuations in autonomous or controlled motivation. In contrast, at the person level, the results revealed that higher levels of autonomy support perceptions tended to be significantly associated with higher levels of autonomous motivation, and lower levels of controlled motivation over the course of the study. These results also supported the results from our preliminary analyses in showing that female participants tended to present lower levels of controlled motivation throughout the study.

\section{Outcomes}

As shown in Table 3, the IC associated with the alternative models led to diverging conclusions in relation to the role of motivation trajectories in the prediction of positive affect: The CAIC and BIC supported the presence of associations involving only the random intercepts of the trajectories, whereas the AIC and ABIC supported the presence of associations involving all random variables. However, examination of the parameter estimates associated with these alternative solutions supported the presence of associations involving the random intercept and linear slopes, but not the quadratic 
slopes. The results from this solution are reported in Table 5, and reveal a lack of associations between positive affect and controlled motivation trajectories, but various associations between positive affect and autonomous motivation trajectories. Higher initial levels of autonomous motivation predicted higher initial levels, and more pronounced increases over time, in positive affect trajectories. In addition, more pronounced increases in autonomous motivation also predicted higher average levels of positive affect over the course of the study. In contrast, as shown in Table 3, the results from all IC supported a complete lack of associations between motivation and negative affect trajectories.

Turning our attention to the association between motivation and fatigue, the CAIC and BIC both supported a null effect model, whereas the AIC and ABIC both supported associations limited to the intercepts of the trajectories, a result which is consistent with the parameter estimates of the alternative solutions. Results from this solution are reported in Table 5. These results first revealed that occasionspecific fluctuations in levels of controlled motivation shared positive associations with occasionspecific fluctuations in levels of fatigue. In addition, person-specific levels of autonomous motivation predicted lower levels of fatigue over the course of the study, whereas person-specific levels of controlled motivation predicted higher levels of fatigue over the course of the study.

In terms of learning, the AIC, ABIC, and an examination of parameter estimates all supported the presence of associations involving the linear, but not quadratic, slopes of the trajectories, whereas the CAIC and BIC rather suggested a lack of associations between these variables. Results from the retained model allowing for associations involving the random intercepts and linear slopes of both trajectories are reported in Table 5. These results first revealed a lack of occasion-specific associations between learning and motivation, a lack of associations involving controlled motivation, and a lack of associations involving the linear slope of learning trajectories. In contrast, these results revealed that higher initial levels of autonomous motivation, as well as more pronounced increases over time in autonomous motivation levels, both predicted higher levels of learning over the course of the study.

In terms of satisfaction, the AIC and ABIC both supported a null effect model, whereas the CAIC, BIC, and an examination of parameter estimates supported associations involving the random intercept of the motivation and satisfaction trajectories. Likewise, in terms of engagement, the AIC and ABIC both supported the presence of associations involving the quadratic slope of autonomous motivation, 
whereas the CAIC, BIC and an examination of parameter estimates supported associations involving the random intercept of the motivation and engagement trajectories. The results from these two solutions (involving intercept associations) are reported in Table 5 and reveal similar results. First, both solutions revealed a lack of occasion-specific associations, and a lack of associations involving controlled motivation. Second, both solutions revealed that higher initial levels of autonomous motivation predicted higher levels of satisfaction and engagement over the course of the study.

\section{Discussion}

The benefits of autonomous motivation for numerous work and educational outcomes have been largely documented in past studies (Deci et al., 2017; Guay et al., 2008). Conversely, controlled motivation is generally associated with more detrimental outcomes (Ryan \& Deci, 2017). However, with few exceptions (Gillet et al., 2018a), prior research has largely ignored the dynamic nature of motivation, especially in the context of professional training programs. The current research sought to address this limitation by identifying of autonomous and controlled motivation trajectories over the course of a fourteen-week professional training program. We also examined trajectories of trainees' perceived autonomy support from their trainer and considered their role in the prediction of motivation trajectories. Finally, the relations between these motivation trajectories and training-specific outcomes (positive and negative affect, fatigue, engagement, learning, and satisfaction) were also considered.

\section{Longitudinal Trajectories of Autonomous and Controlled Motivation}

In a recent study, Gillet et al. (2018a) identified three longitudinal profiles representing motivation trajectories (i.e., high, moderate, and low) during a vocational training program (41 weeks).

Unfortunately, from a professional development and training perspective, these scholars focused on students (i.e., upcoming police officers enrolled in a vocational training program), rather than on workers enrolled in a professional training program. When considering the professional training context, our results revealed that the autonomous motivation trajectories observed in this sample were, on the average, characterized by high initial levels, a moderate growth until reaching an inflection point located 2.35 months after the start of the training, and then a slow decrease till the end of the training, thus only partially supporting Hypothesis 1 . In contrast, the controlled motivation trajectory was characterized by relatively low initial levels remaining stable over time, thus falling to support 


\section{Hypothesis 1.}

In terms of autonomous motivation, these results revealed that changes were slightly more pronounced during the earlier stages of training, as already demonstrated by Gillet et al. (2018a), thus reinforcing the idea that autonomous motivation might display some reactivity to the professional training context (Fernet et al., 2020a; Vallerand, 1997). However, it is important to keep in mind that the observed fluctuations remained minimal, which is aligned with previous results showing that membership into work (Fernet et al., 2020a) and educational (Gillet et al., 2017b) motivation profiles tended to remain relatively stable over time. These slight changes in autonomous motivation associated with the first weeks of professional training could possibly be explained by the fact that trainees initially discover a new environment to which they have to adapt (Gillet et al., 2018a). In the present study, it is noteworthy that trainees present high initial levels of autonomous motivation at the beginning of the training program and slightly increasing trajectories. This suggests that the training context tended to, at least initially, match their positive expectations. Once the training context becomes more familiar however, these trajectories become more stable (Gillet et al., 2018a), before showing a slight decrease as the end of the program draws closer. This process seems to correspond to the Matching scenarios identified in the organizational socialization literature as describing the process via with a number of employees adapt to a new workplace (e.g., Solinger et al., 2013), but as applied to the training context.

The slight decrease in autonomous motivation observed later might reflect either an exposure to less intrinsically appealing tasks near the end of the program (e.g., evaluations) or, simply, the anticipation of the end of the training period. More generally, the autonomous motivation trajectory identified at the end of the training program is aligned with the evolution of students' autonomous motivation generally depicted in the SDT literature: Students' generally display high levels of autonomous motivation during the first years of schooling, and these levels tend to decrease as they progress through school (Gillet et al., 2012b; Leroy \& Bressoux, 2016).

In terms of controlled motivation, the present results are aligned with those from past research showing a moderate to high level of rank-order stability over time (Fernet et al., 2012; Jungert et al., 2018; Lopes \& Chambel, 2017). They are also consistent with prior findings demonstrating that 
membership into work (Fernet et al., 2020a) and educational (Gillet et al., 2017b) motivation profiles characterized by low levels of controlled motivation remain relatively stable over time. Finally, they confirm that controlled motivation trajectories are characterized by low and fairly stable levels over time (Opdenakker et al., 2012). However, these average trajectories are likely to mask between-trainee variability (Gillet et al., 2018a; Nishimura \& Sakurai, 2017). In addition, it is noteworthy that the two forms of controlled motivation (introjected and external regulations) proposed by SDT might follow distinct trajectories over time (Leroy \& Bressoux, 2016).

The theoretical perspectives used to guide our study and presented in the introduction, as well as the convergence between our results and those obtained in previous research highlighted in the previous paragraphs lend confidence in the possible generalizability of our results across various professional training contexts based on a voluntary enrollment process (as mandatory participation is likely to result in distinct motivational processes, at least from the perspective of SDT: Ryan \& Deci, 2017). Still, despite these encouraging notes it remains impossible, based solely on the present sample, to clearly determine the true extent to which the current results can be clearly expected to generalize across different training (all participants were involved in the same professional training program seeking to develop focus group animation skills), professional (although participants came from a variety of occupational groups, they all worked in the same organization, namely a departmental fire service), and cultural (France) contexts considered here. In France, most people entering this kind of professional training have a similar professional background and may thus be already familiar with the specific context that characterizes the training sessions, which may have led to an overestimation of the stability of the longitudinal autonomous and controlled motivation trajectories. Thus, although trainees' engagement into their professional training activities seems not to be driven by internal or external pressures, future research is needed to assess the extent to which the current results generalize to other populations and types of training program.

\section{Perceived Autonomy Support as a Predictor of Motivation Trajectories}

Our results showed that autonomous and controlled motivation trajectories were relatively independent from participants' stable demographic characteristics (age, level of education, schedule: Full-time vs. part-time, tenure, and status: Manager vs. non manager). In fact, the only statistically 
significant association was related to sex, showing that females tended to display lower initial levels of controlled motivation relative to males, a result that matches those from past research (Senécal et al., 2001; Vallerand, 1997). More importantly, however, the present findings supported the role of trainees' perceptions of autonomy-supportive behaviors from their trainer in the prediction of their autonomous and controlled motivation trajectories.

First, and supporting Hypothesis 2, our results revealed an average trajectory of autonomy support characterized by high initial levels ( 4.114 on a 1 to 5 scale) and a slow increase over time. This is line with past longitudinal investigations showing that autonomy-supportive behaviors tended to increase over time (e.g., Cheon \& Reeve, 2015; Langdon et al., 2017; Reeve \& Cheon, 2016; Zhang et al., 2020), which might reflect either the fact that trainers gain experience or start to better know the trainees and their idiosyncratic needs for support (Day \& Sin, 2011; Pelletier \& Vallerand, 1996). Second, and supporting Hypotheses 3 and 4, higher levels of perceived autonomy support were associated with higher levels of autonomous motivation and lower levels of controlled motivation over the course of the training program. This matches previous results showing that individuals' perceptions of autonomy-supportive behaviors from their teachers or work supervisors predicted increases in autonomous motivation and decreases in controlled motivation (Núñez \& León, 2015; Slemp et al., 2018). However, to the best of our knowledge, this is the first study to demonstrate an association between trainees' perceptions of autonomy support and their longitudinal motivation trajectories. Thus, trainees exposed to more autonomy-supportive behaviors from their trainer were more likely to invest efforts into their professional training activities for autonomous reasons rather than for controlled reasons (Ryan \& Deci, 2017).

These positive effects of autonomy support on autonomous motivation and these negative effects on controlled motivation may be explained by the fact that supervisors' autonomy-supportive behaviors facilitate the satisfaction of individuals' psychological needs for autonomy, competence, and relatedness, and limit the frustration of these needs (Deci et al., 2017). Autonomy-supportive behaviors also tend to foster autonomous motivation because they enhance trainees' sense that their professional training is meaningful, interesting, and fun (Deci et al., 1989). More generally, these results concur with the premises of SDT in that perceptions of autonomy support are associated with 
adaptive functioning (Gagné \& Deci, 2005).

\section{Outcomes of the Motivation Trajectories}

The present results clearly support the importance of autonomous motivation trajectories in the prediction of various outcomes relevant to the training context (positive and negative affect, fatigue, engagement, learning, and satisfaction). Thus, higher levels of autonomous motivation predicted higher levels of positive affect, learning, satisfaction, and engagement over the course of the training program, and increases over time in levels of positive affect. In addition, more pronounced increases in autonomous motivation also predicted higher average levels of positive affect and learning over the course of the training program. Finally, although levels of autonomous motivation did not present any statistically significant association with negative affect, they still predicted lower levels of fatigue over the course of the training program. These results partially support Hypothesis 5, and are generally aligned with SDT's propositions (Ryan \& Deci, 2017) and previous research (Deci et al., 2017; Gagné $\&$ Deci, 2005) regarding the expected benefits of autonomous motivation. However, the restricted time lag considered in this study might have made it harder to detect effects emerging over a longer time frame (Gillet et al., 2018a). This time range limited us to the detection of more immediate benefits (14 weeks) associated with high levels of autonomous motivation.

It is noteworthy that the effects of autonomous motivation were found to differ as a function of the outcomes considered. Interestingly, prior studies (e.g., Gillet et al., 2017a) also showed that the links between autonomous motivation and work outcomes tended to differ as a function of the type of outcomes considered. For this reason, it would be particularly informative for future studies to also consider cognitive factors (e.g., memory abilities, attentional abilities) identified as key predictors of learning, performance, and training transfer, and that might be even easier to target for intervention purposes (Manoli et al., 2020; Räisänen \& Räkköläinen, 2014). More generally, these additional investigations are necessary to verify the possibility that the benefits of autonomous motivation might be circumscribed to some outcomes (e.g., positive affect, learning), with only a limited influence on others (e.g., negative affect).

Our results also revealed that occasion-specific fluctuations in levels of controlled motivation were positively associated with occasion-specific fluctuations in levels of fatigue. Furthermore, average 
person-specific levels of controlled motivation also predicted higher average levels of fatigue over the course of the training program. In contrast, controlled motivation was not significantly associated with any of the other outcomes. These results thus only partially support Hypothesis 6 and SDT's expectations (Ryan \& Deci, 2017). On the one hand, they confirm the role of controlled motivation for the prediction of undesirable outcomes (e.g., fatigue) relative to more desirable ones (i.e., positive affect, learning, engagement, and satisfaction). Similar findings have been observed in prior research conducted in the educational and work areas (Deci et al., 2017; Guay et al., 2008). On the other hand, they fail to support the role of controlled motivation on negative affect. Yet, this effect has been already demonstrated in past studies (e.g., Gillet et al., 2013d). However, some studies also showed that, contrary to expectations, controlled forms of motivation did not always lead to negative outcomes (e.g., Parker et al., 2010). Interestingly, emerging person-centered studies have shown that controlled forms of motivation may sometimes be associated with positive outcomes (e.g., lower levels of negative affect), but only when accompanied by similarly high levels of autonomous motivation (e.g., Fernet et al., 2020a; Gillet et al., 2017a b), underscoring the importance of studying behavioral regulations in combination. Future studies focusing on the potential synergetic effects of autonomous and controlled motivations would thus be useful to improve our understanding of the links between controlled motivation and outcomes.

\section{Outcome Trajectories}

Although this was not a core objective of the present study, our results provided important information related to the shape of the longitudinal trajectories of each outcome considered over the course of the training program. These results show the value of adopting such a multidimensional dynamic perspective when studying training effects in supporting the idea that various psychological characteristics tend to follow highly differentiated trajectories over the course of a training program.

First, our results revealed high and stable levels of engagement, and low and stable levels of fatigue, suggesting that in this professional training program, there was a relatively good fit between demands and trainees' characteristics (Cable \& DeRue, 2002). Likewise, Gillet et al. (2019) previously showed that work engagement profiles were highly stable over time (see also Mäkikangas et al., 2012, 2013). Such results are not surprising given that engagement is conceptualized as an 
allegedly stable affective-cognitive state (Schaufeli et al., 2002). Similar findings are also reported in the literature for fatigue (Bossola et al., 2017; Picariello et al., 2020) and burnout (Lee \& Lee, 2018; Salmela-Aro \& Upadyaya, 2014). Consistent with evidence from socialization research, these results may also suggest that trainees could have reached a state of equilibrium because they have learned how to cope with training demands as part of prior professional training programs (Dunford et al., 2012) and were able to benefit, in the present study, from high levels of autonomy-supportive behaviors from their trainer.

In addition, our results revealed that positive affect followed longitudinal trajectories characterized by high initial levels and slow linear increases over time. In contrast, negative affect followed a quadratic trajectory characterized by initially low levels followed by a small increase until reaching an inflection point 1.39 month after the beginning of the training program, and finally by a small decrease until the end of the training. These results contrast with those reported by Rogers et al. (2018), who showed that students' levels of positive affect decreased during the semester, but that their levels of negative affect remained stable. The present results suggested that trainees seemed to be happy and excited about the opportunity to learn new skills (i.e., positive affect). However, they may come to face unanticipated challenges (e.g., new routines which may be less structured and more rigorous, increased decision-making responsibilities), which could explain the initial increases in negative affect observed early in the study. Indeed, this initial increase in trainees' levels of negative affect may reflect a gradual process whereby workloads, concerns, and other stressors initially accumulate to challenge trainees' ability to cope and self-regulate with the initial demands of the professional training (Cable \& DeRue, 2002; Conley et al., 2014). However, once this initial misfit is resolved, which may be helped by the excitement associated with the opportunity to learn new skills (as illustrated by the increasing levels of positive affect), trainees' may progressively come to reach a new stage of person-environment fit, leading to decreases in their levels negative affect.

For learning, the results revealed initially moderately high average levels, followed by an increase until reaching an inflection point 1.73 month after the beginning of the training program, and finally by a decrease until the end of the training. Although learning (or performance) is known to be a dynamic component (Bass, 1960), it is only over the past two decades that scholars have directly 
examined learning trajectories over time (Sturman, 2007). Past studies have shown that learning initially increases, plateaus, and finally declines (i.e., an inverted U-shaped relationship; Minbashian et al., 2013; van der Schaaf et al., 2011). The role of work experience in accounting for the initial increase in learning that occurs when trainees begin a training is well known (Khan \& Minbashian, 2019). Indeed, Murphy's (1989) two-stage model contends that when trainees begin a training, they enter a transition stage characterized by the learning of new skills and tasks. Trainees' learning quickly increases as they acquire more experience. When the tasks they perform become well learned, their learning begins to plateau and they enter a maintenance stage. However, this model does not explain why learning decreases at later stages. First, at later stages, trainees may experience decline in cognitive abilities, thus negatively influencing learning (Horn, 1991). The decrease in learning observed at later stages has also been attributed to the effects of changes in motivation (Minbashian \& Luppino, 2014). Indeed, as mentioned above, the present results suggest that the decreases in autonomous motivation trajectories observed at the end of the training program may explain these learning declines over time. Trainees may experience decreases in autonomous motivation over time as they find themselves performing more repetitive tasks (e.g., the honeymoon-hangover effect; Boswell et al., 2005), explaining the decline in learning that occurs at later stages of training.

Finally, we found an average satisfaction trajectory characterized by initially high levels, by a slight decrease early in the training program, and finally by marked increases starting 1.02 month after the beginning of the training program. Indeed, after beginning a professional training program, employees may show a trend of decline in satisfaction referred to as the Hangover effect in the organizational socialization literature (Boswell et al., 2005). One prominent explanation for the emergence of this effect is the contrast experienced between a new training and a previous one, or between one's high expectations and the reality (Solinger et al., 2013). According to this argument, trainees may compare their new training program with a previous one, but having in mind the result of this previous program in terms of skills learned, or in relation to their own positive expectations leading them to enroll in this program in the first place. If the comparison leads to a contrast effect (e.g., the initial content of the current training is seen as lacking), training satisfaction might decrease at the beginning of the program. Moreover, beginning a new professional training is a stressful 
situation and can represent a threat to existing resources (e.g., competence; Hobfoll, 1989) as trainees encounter new challenges (e.g., mastering new skills and tasks, learning to cooperate).

However, after this initial period, a gradual increase in training satisfaction may set in when the new training starts to unfold in a way that better matches trainees' expectations. This tendency might be further reinforced by the new resources provided from their trainers and colleagues (e.g., autonomy support), which help to facilitate their socialization into the program (Solinger et al., 2013). Trainees might also become able to capitalize on their own personal resources (e.g., autonomous motivation) to deal more efficiently with training demands (Valero \& Hirschi, 2019). Based on conservation of resources theory (Hobfoll, 1989), existing resources can also promote the accumulation of further resources, leading to resource gain spirals. After a short challenging period, trainees may thus start to accumulate resources and to more efficiently adopt the goals and rules of the training (Solinger et al., 2013). Following this logic, trainees could gradually perceive a better fit between their characteristics and those of the training context, and experience increasing capacity to master challenges, leading to an increasingly positive overall evaluation of the training program.

Interestingly, Valero and Hirschi (2019) showed that, for a majority of participants engaged in a vocational training program, the development of satisfaction during the four months following the beginning of the program also indicated a Hangover effect. However, a third of participants also showed high and stable levels of satisfaction. These scholars also demonstrated that trainees in the high stable satisfaction group were characterized by more contextual and personal resources (i.e., core self-evaluations, perceived social support, perceived person-job fit, and occupational self-efficacy). As in the present study, these findings illustrate the importance of a diverse and complementary set of social (e.g., autonomy support) and motivational (e.g., autonomous motivation) resources to facilitate a positive trajectory of satisfaction over the course of a professional training program.

\section{Limitations and Future Directions}

Although the present research offers the first investigation of the characteristics, determinants, and consequences of trainees' autonomous and controlled motivation trajectories over the course of a professional training program, it has some limitations. First, this study capitalized on self-report measures, which may have been influenced by self-report biases and social desirability. Upcoming 
studies should incorporate more objective indicators of trainees' behaviors (e.g., absenteeism, performance), as well as ratings, relevant to the training context, obtained from multiple informants (e.g., trainers' ratings of performance and supervisors' ratings of transfer). Second, this study involved a sample of workers undergoing a 14-week professional training program to develop focus group facilitator skills. Other studies are still needed to confirm the generalizability of the trajectories identified in the present research and their relations with a broader range of determinants and consequences across a variety of countries, cultures, and occupational groups (e.g., nurses, sales employees, managers) and types of training programs. Finally, we only considered a single predictor of autonomous and controlled motivation trajectories (trainees' perceived autonomy support). It would be worthwhile for future studies to consider a greater variety of training-related (e.g., learning context, pedagogical approaches, peer support; Caesens et al., 2020) or individual (e.g., perfectionism, workaholism; Huyghebaert et al., 2018a) predictors.

\section{Practical Implications}

Our results also show that organizations, managers, and trainers ought to be particularly attentive to trainees characterized by low levels of autonomous motivation and high levels of controlled motivation. Indeed, these individuals are exposed to higher risks of maladaptive functioning (e.g., lower levels of positive affect and learning, higher levels of fatigue). Changes in a training program designed to increase the levels of trainers' autonomy-supportive behaviors sustainably may be particularly useful to help trainees internalize in a self-determined manner the skills, values, and expected behaviors they need to perform their tasks (Gillet et al., 2012a). Autonomy support is related to the presence of alternative choices and the provision of a rationale for engaging in activities, as well as to the minimization of the use of controlling behaviors and evaluative communications (Deci et al., 1989). Furthermore, informal mentoring activities and social events might also help to build a stronger workplace support climate among colleagues (Newman et al., 2012). The endpoint of these strategies is to create a workplace and training context characterized by supportive and positive interactions among colleagues (Newman et al., 2012).

\section{References}

Asparouhov, T., \& Muthén, B. (2019). Latent variable centering of predictors and mediators in 
multilevel and time-series models. Structural Equation Modeling, 26, 119-142.

https://doi.org/10.1080/10705511.2018.1511375

Baltes, P.B. (1997). On the incomplete architecture of human ontogeny: Selection, optimization, and compensation as foundation of developmental theory. American Psychologist, 52, 366-380. https://doi.org/10.1037/0003-066X.52.4.366

Barling, J., \& Frone, M.R. (2017). If only my leader would just do something! Passive leadership undermines employee well- being through role stressors and psychological resource depletion. Stress and Health, 33, 211-222. https://doi.org/10.1002/smi.2697

Barrow, J.C. (1976). Worker performance and task complexity as causal determinants of leader behavior style and flexibility. Journal of Applied Psychology, 61, 433-440. https://doi.org/10.1037/0021-9010.61.4.433

Bass, B.M. (1960). Leadership, psychology, and organizational behavior. Harper.

Beier, M.E., \& Kanfer, R. (2009). Motivation in training and development: A phase perspective. In S.W.J. Kozlowski \& E. Salas (Eds.), Learning, training, and development in organizations (pp. 6597). Psychology Press.

Belenky, G., Wesensten, N.J., Thorne, D.R., Thomas, M.L., Sing, H.C., Redmond, D.P., \& Balkin, T.J. (2003). Patterns of performance degradation and restoration during sleep restriction and subsequent recovery: A sleep dose- response study. Journal of Sleep Research, 12, 1-12. https://doi.org/10.1046/j.1365-2869.2003.00337.x

Black, A.E., \& Deci, E.L. (2000). The effects of instructors' autonomy support and students' autonomous motivation on learning organic chemistry: A self-determination theory perspective. Science Education, 84, 740-756. https://doi.org/10.1002/1098-237X(200011)84:6<740::AIDSCE4>3.0.CO;2-3

Blais, A.-R., Gillet, N., Houle, S.A., Comeau, C., \& Morin, A.J.S. (2020). Work fatigue profiles: Nature, implications, and associations with psychological empowerment. Frontiers in Psychology, 11, 596206. https://doi.org/10.3389/fpsyg.2020.596206

Bossola, M., Di Stasio, E., Antocicco, M., Pepe, G., Marzetti, E., \& Vulpio, C. (2017). 1-year course of fatigue in patients on chronic hemodialysis. International Urology \& Nephrology, 49, 727-734. 
https://doi.org/10.1080/13548506.2019.1653477

Boswell, W.R., Boudreau, J.W., \& Tichy, J. (2005). The relationship between employee job change and job satisfaction: The honeymoon-hangover effect. Journal of Applied Psychology, 90, 882-892. https://doi.org/10.1037/0021-9010.90.5.882

Cable, D.M., \& DeRue, D.S. (2002). The convergent and discriminant validity of subjective fit perceptions. Journal of Applied Psychology, 87, 875-884. https://doi.org/10.1037/00219010.87 .5 .875

Caesens, G., Gillet, N., Morin, A.J.S., Houle, S.A., \& Stinglhamber, F. (2020). A person- centred perspective on social support in the workplace. Applied Psychology: An International Review, 69, 686-714. https://doi.org/10.1111/apps.12196

Cai, S., Lin, H., Hu, X., Cai, Y.-X., Chen, K., \& Cai, W.-Z. (2018). High fatigue and its associations with health and work related factors among female medical personnel at 54 hospitals in Zhuhai, China. Psychology, Health \& Medicine, 23, 304-316. https://doi.org/10.1080/13548506.2017.1361038

Cheon, S.H., \& Reeve, J. (2015). A classroom-based intervention to help teachers decrease students' amotivation. Contemporary Educational Psychology, 40, 99-111.

https://doi.org/10.1016/j.cedpsych.2014.06.004

Cheon, S.H., Reeve, J., Lee, Y., Ntoumanis, N., Gillet, N., Kim, B.R., \& Song, Y.-G. (2019). Expanding autonomy psychological need states from two (satisfaction, frustration) to three (dissatisfaction): A classroom-based intervention study. Journal of Educational Psychology, 111, 685-702. https://doi.org/10.1037/edu0000306

Colquitt, J.A., LePine, J.A., \& Noe, R.A. (2000). Toward an integrative theory of training motivation: A meta-analytic path analysis of 20 years of research. Journal of Applied Psychology, 85, 678-707. https://doi.org/10.1037/0021-9010.85.5.678

Conley, C.S., Kirsch, A.C., Dickson, D.A., \& Bryant, F.B. (2014). Negotiating the transition to college: Developmental trajectories and gender differences in psychological functioning, cognitiveaffective strategies, and social well-being. Emerging Adulthood, 2, 195-210. https://doi.org/10.1177/2167696814521808 
Day, D.V., \& Sin, H.-P. (2011). Longitudinal tests of an integrative model of leader development: Charting and understanding developmental trajectories. The Leadership Quarterly, 22, 545-560. https://doi.org/10.1016/j.leaqua.2011.04.011

Day, D.V., Harrison, M.M., \& Halpin, S.M. (2009). An integrative approach to leader development: Connecting adult development, identity and expertise. Routledge/Taylor \& Francis Group.

Deci, E.L., \& Ryan, R.M. (2000). The "what" and "why" of goal pursuits: Human needs and the selfdetermination of behavior. Psychological Inquiry, 11, 227-268. https://doi.org/10.1207/S15327965PLI1104_01

Deci, E.L., Connell, J.P., \& Ryan, R.M. (1989). Self-determination in a work organization. Journal of Applied Psychology, 74, 580-590. https://doi.org/10.1037/0021-9010.74.4.580

Deci, E.L., Olafsen, A., \& Ryan, R.M. (2017). Self-determination theory in work organizations: The state of science. Annual Review of Organizational Psychology \& Organizational Behavior, 19-43. https://doi.org/10.1146/annurev-orgpsych-032516-113108

Delrue, J., Mouratidis, A., Haerens, L., De Muynck, G.-J., Aelterman, N., \& Vansteenkiste, M. (2016). Intrapersonal achievement goals and underlying reasons among long distance runners: Their relation with race experience, self-talk, and running time. Psychologica Belgica, 56, 288-310. https://doi.org/10.5334/pb.280

DeRue, D.S., \& Ashford, S.J. (2010). Power to the people: Where has personal agency gone in leadership development? Industrial and Organizational Psychology: Perspectives on Science and Practice, 3, 24-27. https://doi.org/10.1111/j.1754-9434.2009.01191.x

Diseth, Å., Breidablik, H., \& Meland, E. (2018). Longitudinal relations between perceived autonomy support and basic need satisfaction in two student cohorts. Educational Psychology, 38, 99-115. https://doi.org/10.1080/01443410.2017.1356448

Dunford, B.B., Shipp, A.J., Boss, R.W., Angermeier, I., \& Boss, A.D. (2012). Is burnout static or dynamic? A career transition perspective of employee burnout trajectories. Journal of Applied Psychology, 97, 637-650. https://doi.org/10.1037/a0027060

Dysvik, A., \& Kuvaas, B. (2014). Self-determination theory and workplace training and development. In M. Gagné (Ed.), The Oxford handbook of work engagement, motivation, and self-determination theory 
(pp. 218-228). Oxford University Press.

Enders, C.K. (2010). Applied missing data analysis. Guilford.

Fernet, C., Austin, S., \& Vallerand, R.J. (2012). The effects of work motivation on employee exhaustion and commitment: An extension of the JD-R model. Work \& Stress, 26, 213-229. https://doi.org/10.1080/02678373.2012.713202

Fernet, C., Chanal, J., \& Guay, F. (2017). What fuels the fire: Job- or task-specific motivation (or both)? On the hierarchical and multidimensional nature of teacher motivation in relation to job burnout. Work \& Stress, 31, 145163. https://doi.org/10.1080/02678373.2017.1303758

Fernet, C., Litalien, D., Morin, A.J.S., Austin, S., Gagné, M., Lavoie-Tremblay, M., \& Forest, J. (2020a). On the temporal stability of self-determined work motivation profiles: A latent transition analysis. European Journal of Work and Organizational Psychology, 29, 49-63. https://doi.org/10.1080/1359432X.2019.1688301

Fernet, C., Morin, A.J.S., Austin, S., Gagné, M., Litalien, D., Lavoie-Tremblay, M., \& Forest, J. (2020b). Self-determination trajectories at work: A growth mixture analysis. Journal of Vocational Behavior, 121, Article 103473. https://doi.org/10.1016/j.jvb.2020.103473

Fouquereau, E., Morin, A.J.S., Lapointe, É., Mokounkolo, R., \& Gillet, N. (2019). Emotional labour profiles: Associations with key predictors and outcomes. Work \& Stress, 33, 268-294. https://doi.org/10.1080/02678373.2018.1502835

Fredrickson, B.L. (2014). Positive emotions: The good, the bad, the inert, and the complicated. In J. Gruber \& J.T. Moskowitz (Eds.), Positive emotion: Integrating the light sides and dark sides (pp. 535-538). Oxford University Press.

Freund, A.M., \& Baltes, P.B. (2002). Life-management strategies of selection, optimization and compensation: Measurement by self-report and construct validity. Journal of Personality and Social Psychology, 82, 642-662. https://doi.org/10.1037/0022-3514.82.4.642

Frone, M.R., \& Blais, A.-R. (2019). Work fatigue in a non-deployed military setting: Assessment, prevalence, predictors, and outcomes. International Journal of Environmental Research and Public Health, 16, 2892-2917. https://doi.org/10.3390/ijerph16162892

Frone, M.R., \& Tidwell, M.-C.O. (2015). The meaning and measurement of work fatigue: 
Development and evaluation of the Three-Dimensional Work Fatigue Inventory (3D-WFI). Journal of Occupational Health Psychology, 20, 273-288. https://doi.org/10.1037/a0038700

Gagné, M., \& Deci, E.L. (2005). Self-determination theory and work motivation. Journal of Organizational Behavior, 26, 331-362. https://doi.org/10.1002/job.322

Gagné, M., Forest, J., Vansteenkiste, M., Crevier-Braud, L., van den Broeck, A., Aspeli, A.K., Bellerose, J., Benabou, C., Chemolli, E., Güntert, S.T., Halvari, H., Indiyastuti, D.L., Johnson, P. A., Molstad, M.H., Naudin, M., Ndao, A., Olafsen, A.H., Roussel, P., Wang, Z., \& Westbye, C. (2015). The Multidimensional Work Motivation Scale: Validation evidence in seven languages and nine countries. European Journal of Work and Organizational Psychology, 24, 178-196. https://doi.org/10.1080/1359432X.2013.877892

Gillet, N., Becker, C., Lafrenière, M.-A., Huart, I., \& Fouquereau, E. (2017a). Organizational support, job resources, soldiers' motivational profiles, work engagement, and affect. Military Psychology, 29, 418-433. https://doi.org/10.1037/mil0000179

Gillet, N., Berjot, S., \& Paty, E. (2010). Profils motivationnels et ajustement au travail : vers une approche intra-individuelle de la motivation. Le Travail Humain, 73, 141-162. https://doi.org/10.3917/th.732.0141

Gillet, N., Berjot, S., Vallerand, R.J., \& Amoura, S. (2012a). The role of autonomy support and motivation in the prediction of interest and dropout intentions in two real-life settings. Basic and Applied Social Psychology, 34, 278-286. https://doi.org/10.1080/01973533.2012.674754

Gillet, N., Caesens, G., Morin, A.J.S., \& Stinglhamber, F. (2019). Complementary variable- and person-centered approaches to the dimensionality of work engagement: A longitudinal investigation. European Journal of Work and Organizational Psychology, 28, 239-258. https://doi.org/10.1080/1359432X.2019.1575364

Gillet, N., Forest, J., Benabou, C., \& Bentein, K. (2015a). The effects of organizational factors, psychological need satisfaction and thwarting, and affective commitment on workers' well-being and turnover intentions. Le Travail Humain, 78, 119-140. https://doi.org/10.3917/th.782.0119

Gillet, N., Fouquereau, E., Lafrenière, M.-A.K., \& Huyghebaert, T. (2016). Examining the roles of work autonomous and controlled motivations on satisfaction and anxiety as a function of role 
ambiguity. The Journal of Psychology, 150, 644-655.

https://doi.org/10.1080/00223980.2016.1154811

Gillet, N., Gagné, M., Sauvagère, S., \& Fouquereau, E. (2013a). The role of supervisor autonomy support, organizational support, and autonomous and controlled motivation in predicting employees' satisfaction and turnover intentions. European Journal of Work and Organizational Psychology, 22, 450-460. https://doi.org/10.1080/1359432X.2012.665228

Gillet, N., Huart, I., Colombat, P., \& Fouquereau, E. (2013b). Perceived organizational support, motivation, and engagement among police officers. Professional Psychology: Research and Practice, 44, 46-55. https://doi.org/10.1037/a0030066

Gillet, N., Lafrenière, M.-A., Huyghebaert, T., \& Fouquereau, E. (2015b). Autonomous and controlled reasons underlying achievement goals: Implications for the $3 \times 2$ achievement goal model in educational and work settings. Motivation and Emotion, 39, 858-875. https://doi.org/10.1007/s11031-015-9505-y

Gillet, N., Lafrenière, M.- A.K., Vallerand, R.J., Huart, I., \& Fouquereau, E. (2014). The effects of autonomous and controlled regulation of performance- approach goals on well- being: A process model. British Journal of Social Psychology, 53, 154-174. https://doi.org/10.1111/bjso.12018

Gillet, N., Morin, A.J.S., \& Reeve, J. (2017b). Stability, change, and implications of students' motivation profiles: A latent transition analysis. Contemporary Educational Psychology, 51, 222-239. https://doi.org/10.1016/j.cedpsych.2017.08.006

Gillet, N., Morin, A.J.S., Huart, I., Odry, D., Chevalier, S., Coillot, H., \& Fouquereau, E. (2018a). Self-determination trajectories during police officers' vocational training program: A growth mixture analysis. Journal of Vocational Behavior, 109, 27-43.

https://doi.org/10.1016/j.jvb.2018.09.005

Gillet, N., Morin, A.J.S., Ndiaye, A., Colombat, P., \& Fouquereau, E. (2020). A test of work motivation profile similarity across four distinct samples of employees. Journal of Occupational and Organizational Psychology, 93, 988-1030. https://doi.org/10.1111/joop.12322

Gillet, N., Morin, A.J.S., Sandrin, E., \& Houle, S.A. (2018b). Investigating the combined effects of workaholism and work engagement: A substantive-methodological synergy of variable-centered 
and person-centered methodologies. Journal of Vocational Behavior, 109, 54-77.

https://doi.org/10.1016/j.jvb.2018.09.006

Gillet, N., Vallerand, R.J., \& Lafrenière, M.-A.K. (2012b). Intrinsic and extrinsic school motivation as a function of age. Social Psychology of Education, 15, 77-95. https://doi.org/10.1007/s11218-011$9170-2$

Gillet, N., Vallerand, R.J., \& Paty, B. (2013c). Situational motivational profiles and performance with elite performers. Journal of Applied Social Psychology, 43, 1200-1210. https://doi.org/10.1111/jasp.12083

Gillet, N., Vallerand, R.J., Amoura, S., \& Baldes, B. (2010). Influence of coaches' autonomy support on athletes' motivation and sport performance: A test of the hierarchical model of intrinsic and extrinsic motivation. Psychology of Sport and Exercise, 11, 155-161. https://doi.org/10.1016/j.psychsport.2009.10.004

Gillet, N., Vallerand, R.J., Lafrenière, M.-A.K., \& Bureau, J.S. (2013d). The mediating role of positive and negative affect in the situational motivation-performance relationship: A test of the selfdetermination and broaden-and-build theories. Motivation and Emotion, 37, 465-479. https://doi.org/10.1007/s11031-012-9314-5

Greenberg, M.T., Weissberg, R.P., O'Brien, M.U., Zins, J.E., Fredericks, L., Resnik, H., \& Elias, M.J. (2003). Enhancing school-based prevention and youth development through coordinated social, emotional, and academic learning. American Psychologist, 58, 466-474. https://doi.org/10.1037/0003-066X.58.6-7.466

Grossman, R., \& Salas, E. (2011). The transfer of training: What really matters. International Journal of Training and Development, 15, 103-120. https://doi.org/10.1111/j.1468-2419.2011.00373.x

Guay, F., Morin, A.J.S., Litalien, D., Howard, J.L., \& Gilbert, W. (2020). Trajectories of selfdetermined motivation during the secondary school: A growth mixture analysis. Journal of Educational Psychology. Early view: https://doi.org/10.1037/edu0000482

Guay, F., Ratelle, C.F., \& Chanal, J. (2008). Optimal learning in optimal contexts: The role of selfdetermination in education. Canadian Psychology, 49, 233-240. https://doi.org/10.1037/a0012758

Hart, S.L., Steinheider, B., \& Hoffmeister, V. E. (2019). Team- based learning and training transfer: 
A case study of training for the implementation of enterprise resources planning software.

International Journal of Training and Development, 23, 135-152.

https://doi.org/10.1111/ijtd.12150

Hobfoll, S.E. (1989). Conservation of resources: A new attempt at conceptualizing stress. American Psychologist, 44, 513-524. https://doi.org/10.1037/0003-066X.44.3.513

Horn, J.L. (1991). Measurement of intellectual capabilities: A review of theory. In K.S. McGrew, J.K. Werder, \& R.W. Woodcock (Eds.), WJ-R technical manual (pp. 197-232). DLM.

Howard, J.L., Gagné, M., Morin, A.J.S., \& Van den Broeck, A. (2016). Motivation profiles at work. Journal of Vocational Behavior, 95-96, 74-89. https://doi.org/10.1016/j.jvb.2016.07.004

Hox, J.J. (2010). Multilevel analysis: Techniques and applications, $2^{\text {nd }}$ Ed. Routledge.

Huyghebaert, T., Fouquereau, E., Lahiani, F.-J., Beltou, N., Gimenes, G., \& Gillet, N. (2018a). Examining the longitudinal effects of workload on ill-being through each dimension of workaholism. International Journal of Stress Management, 25, 144-162. https://doi.org/10.1037/str0000055

Huyghebaert, T., Gillet, N., Fernet, C., Lahiani, F.-J., Chevalier, S., \& Fouquereau, E. (2018b). Investigating the longitudinal effects of surface acting on managers' functioning through psychological needs. Journal of Occupational Health Psychology, 23, 207-222. https://doi.org/10.1037/ocp0000080

Jang, H., Kim, E.J., \& Reeve, J. (2012). Longitudinal test of self-determination theory's motivation mediation model in a naturally occurring classroom context. Journal of Educational Psychology, 104, 1175-1188. https://doi.org/10.1037/a0028089

Jang, H., Kim, E.J., \& Reeve, J. (2016). Why students become more engaged or more disengaged during the semester: A self-determination theory dual-process model. Learning \& Instruction, 43, 27-38. https://doi.org/10.1016/j.learninstruc.2016.01.002

Jungert, T., Van den Broeck, A., Schreurs, B., \& Osterman, U. (2018). How colleagues can support each other's needs and motivation: An intervention on employee work motivation. Applied Psychology: An International Review, 67, 3-29. https://doi.org/10.1111/apps.12110

Kessler, R.C., Barber, C., Beck, A., Berglund, P., Cleary, P.D., McKenas, D., ... Wang, P. (2003). The 
World Health Organization Health and Work Performance Questionnaire (HPQ). Journal of Occupational and Environmental Medicine, 45, 156-174.

https://doi.org/10.1097/01.jom.0000052967.43131.51

Khan, M., \& Minbashian, A. (2019). The effects of ageing on creative performance trajectories. Applied Psychology: An International Review. Early view: https://doi.org/10.1111/apps.12235

Kraiger, K., \& Ford, J.K. (2007). The expanding role of workplace training: Themes and trends influencing training research and practice. In L.L. Koppes (Ed.), Historical perspectives in industrial and organizational psychology (pp. 281-309). Lawrence Erlbaum Associates Publishers.

Langdon, J.L., Schlote, R., Melton, B., \& Tessier, D. (2017). Effectiveness of a need supportive teaching training program on the developmental change process of graduate teaching assistants' created motivational climate. Psychology of Sport and Exercise, 28, 11-23. https://doi.org/10.1016/j.psychsport.2016.09.008

Lee, M.Y., \& Lee, S.M. (2018). The effects of psychological maladjustments on predicting developmental trajectories of academic burnout. School Psychology International, 39, 217-233. https://doi.org/10.1177/0143034318766206

Leroy, N., \& Bressoux, P., (2016). Does amotivation matter more than motivation in predicting mathematics learning gains? A longitudinal study of sixth-grade students in France. Contemporary Educational Psychology, 44-45, 41-53. https://doi.org/10.1016/j.cedpsych.2016.02.001

Lopes, S., \& Chambel, M.J. (2017). Temporary agency workers' motivations and well-being at work: A two-wave study. International Journal of Stress Management, 24, 321-346. https://doi.org/10.1037/str0000041

Mageau, G.A., Sherman, A., Grusec, J.E., Koestner, R., \& Bureau, J.S. (2017). Different ways of knowing a child and their relations to mother- reported autonomy support. Social Development, 26, 630-644. https://doi.org/10.1111/sode.12212

Mäkikangas, A., Feldt, T., Kinnunen, U., \& Tolvanen, A. (2012). Do low burnout and high work engagement always go hand in hand? Investigation of the energy and identification dimensions in longitudinal data. Anxiety, Stress \& Coping, 25, 93-116. https://doi.org/10.1080/10615806.2011.565411 
Mäkikangas, A., Schaufeli, W., Tolvanen, A., \& Feldt, T. (2013). Engaged managers are not workaholics: Evidence from a longitudinal person-centered analysis. Journal of Work and Organizational Psychology, 29, 135-143. https://doi.org/10.5093/tr2013a19

Manoli, R., Chartaux-Danjou, L., Delecroix, H., Daveluy, W., Torre, F., \& Moroni, C. (2020). The relationship between cognition and vocational training outcome in patients with acquired brain injury: Contribution of machine learning. Applied Neuropsychology: Adult. Early view: https://doi.org/10.1080/23279095.2020.1734809

Marsh, H.W., Lüdtke, O., Nagengast, B., Trautwein, U., Morin, A.J.S., Abduljabbar, A.S., \& Köller, O. (2012). Classroom climate and contextual effects: Conceptual and methodological issues in the evaluation of group-level effects. Educational Psychologist, 47, 106-124. https://doi.org/10.1080/00461520.2012.670488

Maulana, R., Opdenakker, M.- C., \& Bosker, R. (2013). Teacher-student interpersonal relationships do change and affect academic motivation: A multilevel growth curve modelling. British Journal of Educational Psychology, 84, 459-482. https://doi.org/10.1111/bjep.12031

Minbashian, A., \& Luppino, D. (2014). Short-term and long-term within-person variability in performance: An integrative model. Journal of Applied Psychology, 99, 898-914. https://doi.org/10.1037/a0037402

Minbashian, A., Earl, J., \& Bright, J.E.H. (2013). Openness to experience as a predictor of job performance trajectories. Applied Psychology: An International Review, 62, 1-12. https://doi.org/10.1111/j.14640597.2012.00490.x

Morin, A.J.S., Marsh, H.W., Nagengast, B., \& Scalas, L.F. (2014). Doubly latent multilevel analyses of classroom climate: An illustration. The Journal of Experimental Education, 82, 143-167. https://doi.org/10.1080/00220973.2013.769412

Moshman, D. (2003). Developmental change in adulthood. In J. Demick \& C. Andreoletti (Eds.), The Plenum series in adult development and aging. Handbook of adult development (pp. 43-61). Kluwer Academic/Plenum Publishers. https://doi.org/10.1007/978-1-4615-0617-1_3

Murphy, K.R. (1989). Is the relationship between cognitive ability and job performance stable over time? Human Performance, 2, 183-200. https://doi.org/10.1207/s15327043hup0203_3

Muthén, L., \& Muthén, B. (2019). Mplus user's guide. Muthén \& Muthén. 
Nesselroade, J.R. (1991). The warp and woof of the developmental fabric. In R. Downs, L. Liben, \& D.S. Palermo (Eds.), Visions of aesthetics, the environment, and development (pp. 213-240). Erlbaum.

Newman, A., Thanacoody, R., \& Hui, W. (2012). The effects of perceived organizational support, perceived supervisor support and intra-organizational network resources on turnover intentions: A study of Chinese employees in multinational enterprises. Personnel Review, 41, 56-72. https://doi.org/10.1108/00483481211189947

Nishimura, T., \& Sakurai, S. (2017). Longitudinal changes in academic motivation in Japan. Journal of Applied Developmental Psychology, 48, 42-48. https://doi.org/10.1016/j.appdev.2016.11.004

Noe, R.A., Tews, M.J., \& Dachner, A.M. (2010). Learner engagement: A new perspective for enhancing our understanding of learner motivation and workplace learning. The Academy of Management Annals, 4, 279-315. https://doi.org/10.1080/19416520.2010.493286

Núñez, J.L., \& León, J. (2015). Autonomy support in the classroom: A review from self-determination theory. European Psychologist, 20, 275-283. https://doi.org/10.1027/1016-9040/a000234

Nunnally, J., \& Bernstein, I. (1994). Psychometric theory, $3^{\text {rd }}$ Edition. McGraw-Hill.

Olafsen, A.H. (2017). The implications of need-satisfying work climates on state mindfulness in a longitudinal analysis of work outcomes. Motivation and Emotion, 41, 22-37. https://doi.org/10.1007/s11031-016-9592-4

Opdenakker, M.-C., Maulana, R., \& den Brok, P. (2012). Teacher-student interpersonal relationships and academic motivation within one school year: Developmental changes and linkage. School Effectiveness and School Improvement, 23, 95-119. https://doi.org/10.1080/09243453.2011.619198

O'Reilly, C.A., Chatman, J., \& Caldwell, D.F. (1991). People and organizational culture: A profile comparison approach to assessing person-organization fit. Academy of Management Journal, 34, 487-516. https://doi.org/10.2307/256404

Parker, S.L., Jimmieson, N.L., \& Amiot, C.E. (2010). Self-determination as a moderator of demands and control. Journal of Vocational Behavior, 76, 52-67. https://doi.org/10.1016/j.jvb.2009.06.010

Pelletier, L.G., \& Vallerand, R.J. (1996). Supervisors' beliefs and subordinates' intrinsic motivation: A behavioral confirmation analysis. Journal of Personality and Social Psychology, 71, 331-340. 
https://doi.org/10.1037/0022-3514.71.2.331

Pelletier, L.G., Séguin-Lévesque, C., \& Legault, L. (2002). Pressure from above and pressure from below as determinants of teachers' motivation and teaching behaviors. Journal of Educational Psychology, 94, 186-196. https://doi.org/10.1037/0022-0663.94.1.186

Picariello, F., Norton, S., Moss- Morris, R., Macdougall, I.C., \& Chilcot, J. (2020). A prospective study of fatigue trajectories among in- centre haemodialysis patients. British Journal of Health Psychology, 25, 61-88. https://doi.org/10.1111/bjhp.12395

Ployhart, R.E., \& Vandenberg, R.J. (2010). Longitudinal research: The theory, design, and analysis of change. Journal of Management, 36, 94-120. https://doi.org/10.1177/0149206309352110

Räisänen, A., \& Räkköläinen, M. (2014). Assessment of learning outcomes in Finnish vocational education and training. Assessment in Education: Principles, Policy \& Practice, 21, 109-124. https://doi.org/10.1080/0969594X.2013.838938

Rangel, B., Chung, W., Harris, T.B., Carpenter, N.C., Chiaburu, D.S., \& Moore, J.L. (2015). Rules of engagement: The joint influence of trainer expressiveness and trainee experiential learning style on engagement and training transfer. International Journal of Training and Development, 19, 18-31. https://doi.org/10.1111/ijtd.12045

Rast, P., MacDonald, S.W.S., \& Hofer, S.M. (2012). Intensive measurement designs for research on aging. The Journal of Gerontopsychology \& Geriatric Psychiatry, 25, 45-55. https://doi.org/10.1024/1662-9647/a000054

Raudenbush, S.W., \& Bryk, A.S. (2002). Hierarchical linear models. Sage.

Rawski, S.L., \& Conroy, S.A. (2020). Beyond demographic identities and motivation to learn: The effect of organizational identification on diversity training outcomes. Journal of Organizational Behavior, 41, 461-478. https://doi.org/10.1002/job.2439

Reeve, J., \& Cheon, S.H. (2016). Teachers become more autonomy supportive after they believe it is easy to do. Psychology of Sport and Exercise, 22, 178-189. https://doi.org/10.1016/j.psychsport.2015.08.001

Reeve, J., Jang, H.-R., \& Jang, H. (2018). Personality-based antecedents of teachers' autonomy-supportive and controlling motivating styles. Learning and Individual Differences, 62, 12-22. 
https://doi.org/10.1016/j.lindif.2018.01.001

Roberts, Z., Rogers, A., Thomas, C.L., \& Spitzmueller, C. (2018). Effects of proactive personality and conscientiousness on training motivation. International Journal of Training and Development, 22, 126-143. https://doi.org/10.1111/ijtd.12122

Rocchi, M., \& Pelletier, L.G. (2017). The antecedents of coaches' interpersonal behaviors: The role of the coaching context, coaches' psychological needs, and coaches' motivation. Journal of Sport \& Exercise Psychology, 39, 366-378. https://doi.org/10.1123/jsep.2016-0267

Rogers, A.A., Updegraff, K.A., Iida, M., Dishion, T.J., Doane, L.D., Corbin, W.C., Van Lenten, S.A., $\&$ Ha, T. (2018). Trajectories of positive and negative affect across the transition to college: The role of daily interactions with parents and friends. Developmental Psychology, 54, 2181-2192. https://doi.org/10.1037/dev0000598

Ryan, R.M., \& Deci, E.L. (2017). Self-determination theory: Basic psychological needs in motivation, development, and wellness. Guilford.

Sadikaj, G., Rappaport, L.M., Moskowitz, D S., Zuroff, D.C., Koestner, R., \& Powers, T. (2015). Consequences of interpersonal spin on couple-relevant goal progress and relationship satisfaction in romantic relationships. Journal of Personality and Social Psychology, 109, 722-737. https://doi.org/10.1037/pspp0000043

Salmela-Aro, K., \& Upadyaya, K. (2014). Developmental trajectories of school burnout: Evidence from two longitudinal studies. Learning and Individual Differences, 36, 60-68. https://doi.org/10.1016/j.lindif.2014.10.016

Sandrin, E., Gillet, N., Fernet, C., Leloup, M., \& Depin-Rouault, C. (2019). Effects of motivation and workload on firefighters' perceived health, stress, and performance. Stress \& Health, 35, 447-456. https://doi.org/10.1002/smi.2873

Schaufeli, W.B., Salanova, M., González-Romá, V., \& Bakker, A.B. (2002). The measurement of engagement and burnout: A two sample confirmatory factor analytic approach. Journal of Happiness Studies, 3, 71-92. https://doi.org/10.1023/A:1015630930326

Senécal, C., Vallerand, R.J., \& Guay, F. (2001). Antecedents and outcomes of work-family conflict: Toward a motivational model. Personality and Social Psychology Bulletin, 27, 176-186. 
https://doi.org/10.1177/0146167201272004

Shimazu, A., Schaufeli, W.B., Kamiyama, K., \& Kawakami, N. (2015). Workaholism vs. work engagement: The two different predictors of future well-being and performance. International Journal of Behavioral Medicine, 22, 18-23. https://doi.org/10.1007/s12529-014-9410-х

Skinner, E.A., \& Belmont, M.J. (1993). Motivation in the classroom: Reciprocal effects of teacher behavior and student engagement across the school year. Journal of Educational Psychology, 85, 571-581. https://doi.org/10.1037/0022-0663.85.4.571

Slemp, G.R., Kern, M.L., Patrick, K.J., \& Ryan, R.M. (2018). Leader autonomy support in the workplace: A meta-analytic review. Motivation and Emotion, 42, 706-724. https://doi.org/10.1007/s11031-018-9698-y

Sliwinski, M.J. (2008). Measurement- burst designs for social health research. Social and Personality Psychology Compass, 2, 245-261. https://doi.org/10.1111/j.1751-9004.2007.00043.x

Snyder, M. (1992). Motivational foundations of behavioral confirmation. In M.P. Zanna (Ed.), Advances in experimental social psychology (pp. 67-114). Academic Press.

Solinger, O.N., Van Olffen, W., Roe, R.A., \& Hofmans, J. (2013). On becoming (un) committed: A taxonomy and test of newcomer onboarding scenarios. Organization Science, 24, 1640-1661. https://doi.org/10.1287/orsc. 1120.0818

Stawski, R.S., MacDonald, S.W., \& Sliwinski, M.J. (2015). Measurement burst design. The Encyclopedia of Adulthood and Aging, 2, 854-859. https://doi.org/10.1002/9781118521373.wbeaa313

Streiner, D.L. (2003). Starting at the beginning: An introduction to coefficient alpha and internal consistency. Journal of Personality Assessment, 80, 99-103. https://doi.org/10.1207/S15327752JPA8001_18

Sturman, M.C. (2007). The past, present, and future of dynamic performance research. In J.J. Martocchio (Ed.), Research in personnel and human resources management: Vol. 26 (pp. 49-110). Emerald Group Publishing Limited.

Sung, S.Y., \& Choi, J.N. (2014). Do organizations spend wisely on employees? Effects of training and development investments on learning and innovation in organizations. Journal of Organizational 
Behavior, 35, 393-412. https://doi.org/10.1002/job.1897

Thompson, E.R. (2007). Development and Validation of an internationally reliable short-form of the Positive and Negative Affect Schedule (PANAS). Journal of Cross-Cultural Psychology, 38, 227-242. https://doi.org/10.1177/0022022106297301

Training Magazine (2017). 2017 Training Industry Report. https://trainingmag.com/trgmagarticle/2017-training-industry-report/

Valero, D., \& Hirschi, A. (2019). To hangover or not: Trajectories of job satisfaction in adolescent workforce newcomers. European Journal of Work and Organizational Psychology, 28, 150-163. https://doi.org/10.1080/1359432X.2018.1564278

Vallerand, R.J. (1997). Toward a hierarchical model of intrinsic and extrinsic motivation. In M.P. Zanna (Ed.), Advances in experimental social psychology (pp. 271-360). Academic Press.

van der Schaaf, M.E., Warmerdam, E., Crone, E.A., \& Cools, R. (2011). Distinct linear and non-linear trajectories of reward and punishment reversal learning during development: Relevance for dopamine in adolescent decision making. Developmental Cognitive Neuroscience, 1, 578-590. https://doi.org/10.1016/j.den.2011.06.007

van der Vegt, G.S., Bunderson, S., \& Kuipers, B. (2010). Why turnover matters in self-managing work teams: Learning, social integration, and task flexibility. Journal of Management, 36, 1168-1191. https://doi.org/10.1177/0149206309344117

Walsh, B.M., \& Magley, V.J. (2020). Workplace civility training: Understanding drivers of motivation to learn. The International Journal of Human Resource Management, 31, 2165-2187. https://doi.org/10.1080/09585192.2018.1441164

Weiss, H.M. (1978). Social learning of work values in organizations. Journal of Applied Psychology, 63, 711-718. https://doi.org/10.1037/0021-9010.63.6.711

Wigfield, A., \& Eccles, J.S. (2000). Expectancy-value theory of achievement motivation. Contemporary Educational Psychology, 25, 68-81. https://doi.org/10.1006/ceps.1999.1015

Zhang, D., Bobis, J., Wu, X., \& Cui, Y. (2020). The effects of an autonomy-supportive teaching intervention on Chinese physics students and their teacher. Research in Science Education, 50, 645-671. https://doi.org/10.1007/s11165-018-9706-y 

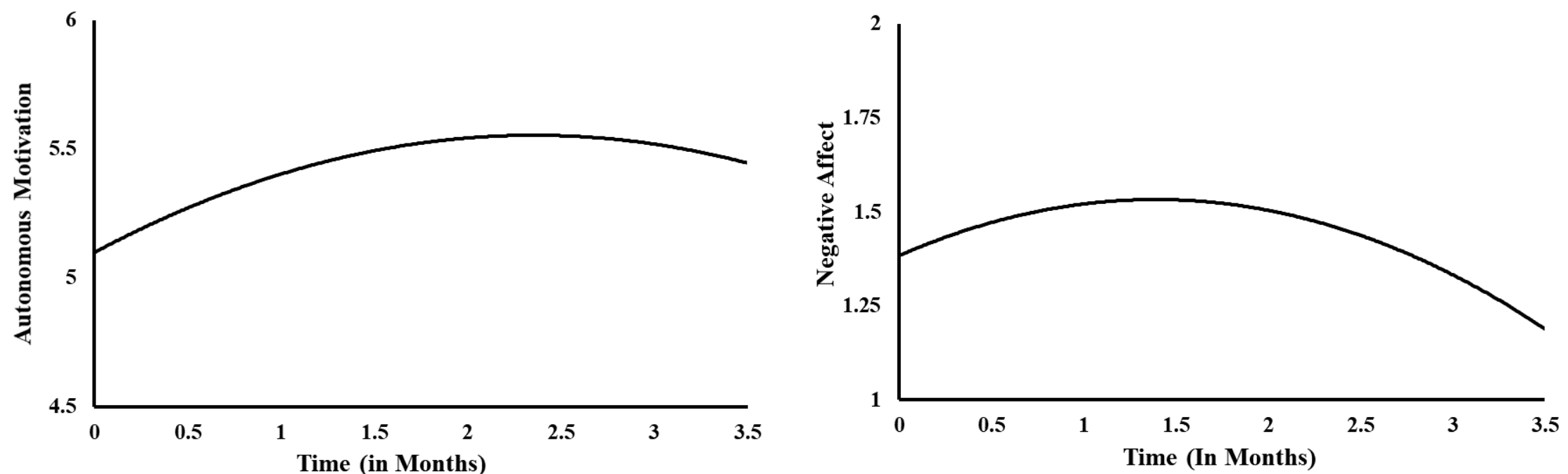

Figure 1a. Autonomous Motivation

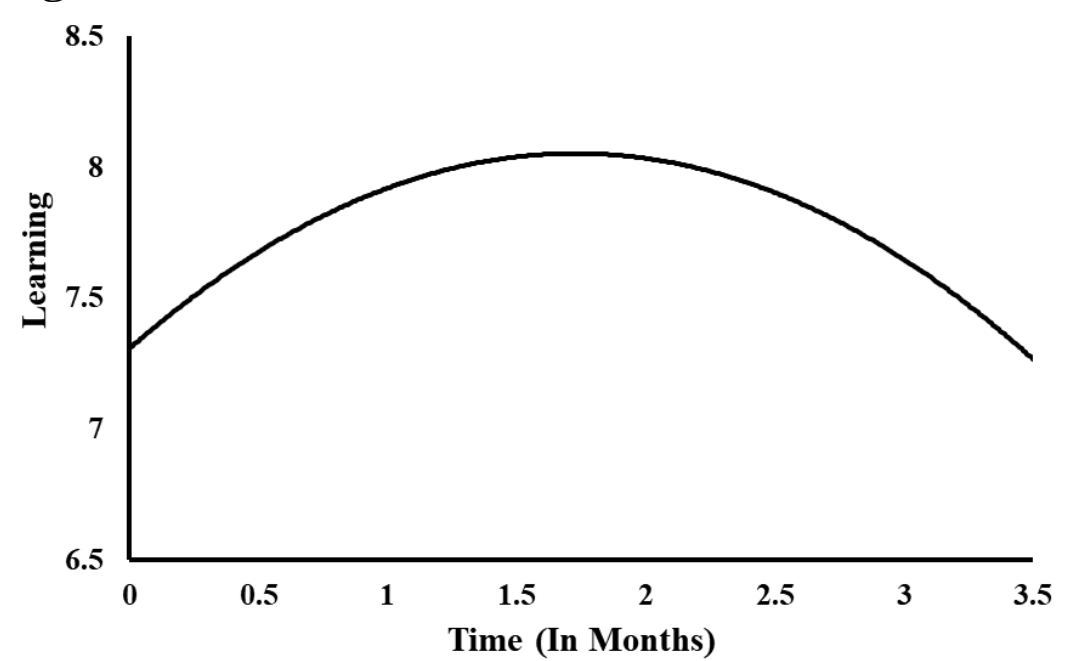

\section{Figure 1c. Learning}

Figure 1b. Negative Affect

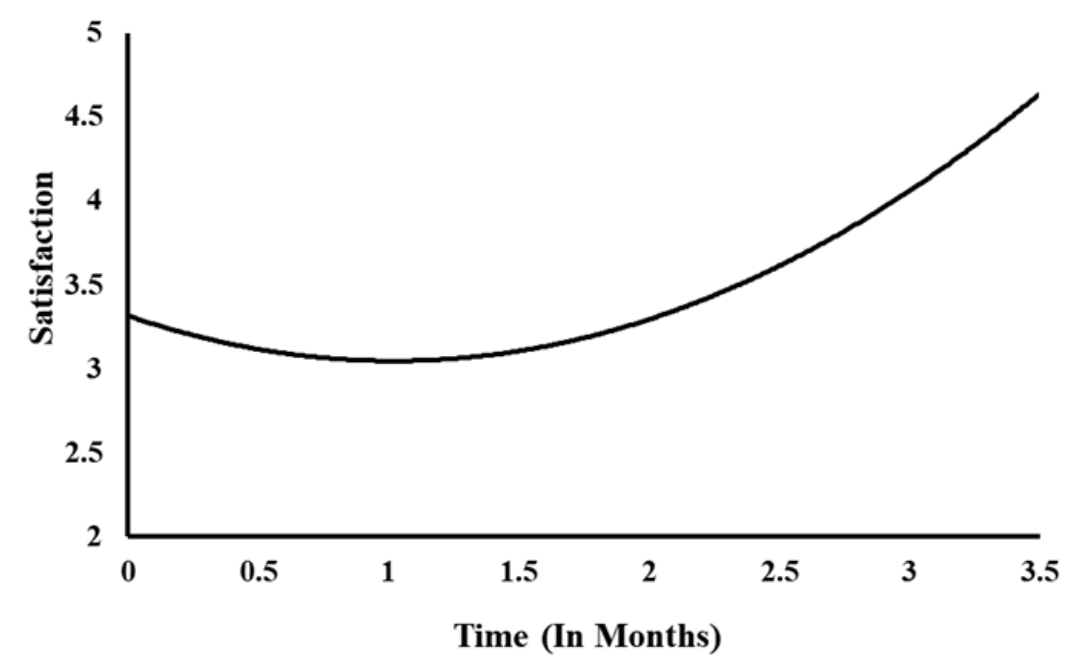

Figure 1d. Satisfaction

Figure 1. Non-Linear Longitudinal Trajectories 
Table 1

Model Fit Results from the Alternative Unconditional Growth Models

\begin{tabular}{|c|c|c|c|c|c|c|c|}
\hline Model & $\log L$ & $\# f p$ & Sc & AIC & CAIC & BIC & $\mathrm{ABIC}$ \\
\hline \multicolumn{8}{|c|}{ Autonomous Motivation } \\
\hline Intercept & -284.425 & 4 & 1.0270 & 576.851 & 595.016 & 591.016 & 578.335 \\
\hline Linear & -281.355 & 7 & .9913 & 576.709 & 608.498 & 601.498 & 579.307 \\
\hline Quadratic & -275.935 & 11 & .9974 & 573.870 & 623.824 & 612.824 & 577.952 \\
\hline \multicolumn{8}{|c|}{ Controlled Motivation } \\
\hline Intercept & -292.260 & 4 & 3.1959 & 592.520 & 610.638 & 606.638 & 593.957 \\
\hline Linear & -292.176 & 7 & 2.6700 & 598.352 & 630.058 & 623.058 & 600.867 \\
\hline Quadratic & -289.587 & 11 & 2.3115 & 601.174 & 650.998 & 639.998 & 605.126 \\
\hline \multicolumn{8}{|c|}{ Autonomy Support ${ }^{A}$} \\
\hline Intercept & -130.751 & 4 & 1.8159 & 269.501 & 287.112 & 283.112 & 270.435 \\
\hline Linear & -118.325 & 7 & 1.3298 & 250.649 & 281.468 & 274.468 & 252.285 \\
\hline \multicolumn{8}{|c|}{ Positive Affect } \\
\hline Intercept & -148.054 & 4 & 1.8318 & 304.109 & 322.274 & 318.274 & 305.593 \\
\hline Linear & -130.278 & 7 & 1.6216 & 274.555 & 306.344 & 299.344 & 277.153 \\
\hline Quadratic & -127.805 & 11 & 1.4167 & 277.610 & 327.564 & 316.564 & 281.691 \\
\hline \multicolumn{8}{|c|}{ Negative Affect } \\
\hline Intercept & -137.041 & 4 & 3.4317 & 282.083 & 300.200 & 296.200 & 283.520 \\
\hline Linear & -127.372 & 7 & 2.5102 & 268.743 & 300.449 & 293.449 & 271.258 \\
\hline Quadratic & -117.131 & 11 & 1.9193 & 256.262 & 306.085 & 295.085 & 260.214 \\
\hline \multicolumn{8}{|l|}{ Fatigue } \\
\hline Intercept & -248.466 & 4 & 2.5800 & 504.932 & 523.081 & 519.081 & 506.400 \\
\hline Linear & -246.164 & 7 & 1.9539 & 506.328 & 538.089 & 531.089 & 508.898 \\
\hline Quadratic & -243.805 & 11 & 1.7340 & 509.610 & 559.521 & 548.521 & 513.648 \\
\hline \multicolumn{8}{|l|}{ Learning } \\
\hline Intercept & -405.151 & 4 & 1.7962 & 818.302 & 836.451 & 832.451 & 819.770 \\
\hline Linear & -400.261 & 7 & 1.3796 & 814.521 & 846.283 & 839.283 & 817.091 \\
\hline Quadratic & -382.823 & 11 & 1.5888 & 787.646 & 837.556 & 826.556 & 791.684 \\
\hline \multicolumn{8}{|l|}{ Satisfaction } \\
\hline Intercept & -303.200 & 4 & 1.6146 & 614.400 & 632.550 & 628.550 & 615.869 \\
\hline Linear & -276.504 & 7 & 1.0469 & 567.008 & 598.769 & 591.769 & 569.577 \\
\hline Quadratic & -242.554 & 11 & 1.3766 & 507.108 & 557.019 & 546.019 & 511.147 \\
\hline \multicolumn{8}{|c|}{ Engagement $^{B}$} \\
\hline Intercept & -53.436 & 4 & 1.2257 & 114.871 & 131.222 & 127.222 & 114.559 \\
\hline
\end{tabular}

Note. $\log \mathrm{L}=$ Model loglikelihood; \#fp = Number of free parameters; Sc = Scaling correction factor for the maximum likelihood robust estimator; $\mathrm{AIC}=$ Akaïke information criterion; $\mathrm{CAIC}=\mathrm{Consistent}$ $\mathrm{AIC} ; \mathrm{BIC}=$ Bayesian information criterion; $\mathrm{ABIC}=$ Sample-size adjusted BIC; ${ }^{\mathrm{A}}$ Autonomy support perceptions were only assessed at three occasions (1-2-4), precluding the estimation of quadratic trajectories; ${ }^{\mathrm{B}}$ Engagement was only assessed at two occasions (1-4), precluding the estimation of linear or quadratic trajectories. 
Table 2

Parameter Estimates (with Standard Errors in Parenthesis) from the Retained Univariate Growth Models

\begin{tabular}{|c|c|c|c|c|c|c|c|c|c|}
\hline & $\begin{array}{l}\text { Autonomous } \\
\text { Motivation }\end{array}$ & $\begin{array}{l}\text { Controlled } \\
\text { Motivation }\end{array}$ & $\begin{array}{l}\text { Autonomy } \\
\text { Support }\end{array}$ & $\begin{array}{l}\text { Positive } \\
\text { Affect }\end{array}$ & $\begin{array}{l}\text { Negative } \\
\text { Affect }\end{array}$ & Fatigue & Learning & Satisfaction & Engagement \\
\hline \multicolumn{10}{|l|}{ Level 1: Burst } \\
\hline Variance & $.222(.032)^{* *}$ & $.317(.095)^{* *}$ & $.075(.022)^{* *}$ & $.092(.017)^{* *}$ & $.088(.023)^{* *}$ & $.171(.050)^{* *}$ & $.413(.108)^{* *}$ & $.100(.017)^{* *}$ & $.036(.008)^{* *}$ \\
\hline \multicolumn{10}{|l|}{ Level 2: Occasion } \\
\hline Residual Variance & $.133(.058)^{*}$ & $.097(.078)$ & $.092(.026)^{* *}$ & $.005(.015)$ & $.001(.024)$ & $.254(.102)^{*}$ & $.565(.375)$ & $.318(.063)^{* *}$ & $.058(.019)^{* *}$ \\
\hline \multicolumn{10}{|l|}{ Level 3: Person } \\
\hline Intercept (I) Mean & \multicolumn{9}{|c|}{$5.099(.154)^{* *} 1.781(.148)^{* *} 4.114(.062)^{* *} 3.599(.064)^{* *}$} \\
\hline I. Variance & $.779(.189)^{* *}$ & $.818(.234)^{* *}$ & $.084(.049)$ & $.140(.045)^{* *}$ & $.166(.095)$ & $.250(.059) * *$ & $.438(.660)$ & $.058(.548)$ & $.165(.000)^{* *}$ \\
\hline Linear (L) Mean & $.386(.223)$ & NA & $.122(.020)^{* *}$ & $.074(.021)^{* *}$ & $.214(.145)$ & NA & $.864(.333)^{* *}$ & $-.529(.230)^{*}$ & NA \\
\hline L. Variance & $.979(.356)^{*}$ & NA & $.001(.007)$ & $.011(.007)$ & $.432(.351)$ & NA & $1.626(5.381)$ & $.962(.845)$ & NA \\
\hline Quadratic (Q) Mean & $-.082(.058)$ & NA & NA & NA & $-.077(.039)^{*}$ & NA & $-.250(.108)^{*}$ & $.259(.083)^{* *}$ & NA \\
\hline Q. Variance & $.059(.025)^{*}$ & NA & NA & NA & $.032(.027)$ & NA & $.262(.328)$ & $.173(.141)$ & NA \\
\hline I-L Covariance & $-.652(.250)^{* *}$ & NA & $.002(.015)$ & $.020(.016)$ & $-.110(.106)$ & NA & $-.304(1.871)$ & $-.232(.596)$ & NA \\
\hline I-Q Covariance & $.163(.066)^{*}$ & NA & NA & NA & $.025(.028)$ & NA & $.102(.482)$ & $.098(.209)$ & NA \\
\hline L-Q Covariance & $-.240(.093)^{* *}$ & NA & NA & NA & $-.117(.226)$ & NA & $-.650(1.329)$ & $-.408(.379)$ & NA \\
\hline \multicolumn{10}{|c|}{ Intraclass Correlations } \\
\hline ICC (Level 2) & .314 & .083 & .440 & .151 & .204 & .378 & .772 & .905 & .228 \\
\hline ICC (Level 3) & .457 & .661 & .302 & .590 & .374 & .370 & .072 & .046 & .635 \\
\hline Variance Level 1 & .229 & .256 & .258 & .259 & .422 & .252 & .156 & .049 & .137 \\
\hline
\end{tabular}

Note. $* p<.05 ; * * p<.01 ;$ ICC $=$ Intraclass correlation coefficient; NA = Not applicable. 
Table 3

Model Fit Results from the Alternative Conditional Growth Models

\begin{tabular}{|c|c|c|c|c|c|c|c|}
\hline Model & $\log \mathrm{L}$ & $\# f p$ & Sc & AIC & CAIC & BIC & $\mathrm{ABIC}$ \\
\hline \multicolumn{8}{|l|}{ Autonomy Support } \\
\hline Null-Effect & -680.270 & 26 & 1.4035 & 1412.539 & 1530.612 & 1504.612 & 1422.186 \\
\hline Intercept-Only Effects & -666.919 & 32 & 1.5935 & 1397.837 & 1543.158 & 1511.158 & 1409.710 \\
\hline Linear Effects & -664.152 & 35 & 1.4850 & 1398.303 & 1557.247 & 1522.247 & 1411.289 \\
\hline All Effects & -661.806 & 40 & 1.4026 & 1403.612 & 1585.263 & 1545.263 & 1418.453 \\
\hline \multicolumn{8}{|l|}{ Positive Affect } \\
\hline Null-Effect & -692.220 & 26 & 1.4840 & 1436.441 & 1554.514 & 1528.514 & 1446.088 \\
\hline Intercept-Only Effects & -677.730 & 30 & 1.3918 & 1415.461 & 1551.699 & 1521.699 & 1426.591 \\
\hline Linear Effects & -671.312 & 34 & 1.3537 & 1410.624 & 1565.027 & 1531.027 & 1423.239 \\
\hline All Effects & -668.833 & 36 & 1.2637 & 1409.666 & 1573.152 & 1537.152 & 1423.023 \\
\hline \multicolumn{8}{|l|}{ Negative Affect } \\
\hline Null-Effect & -679.128 & 30 & 1.6167 & 1418.257 & 1554.495 & 1524.495 & 1429.388 \\
\hline Intercept-Only Effects & -675.816 & 34 & 1.5337 & 1419.631 & 1574.034 & 1540.034 & 1432.246 \\
\hline Linear Effects & -674.041 & 38 & 1.4951 & 1424.082 & 1596.65 & 1558.650 & 1438.181 \\
\hline All Effects & -670.438 & 44 & 1.3946 & 1428.876 & 1628.691 & 1584.691 & 1445.201 \\
\hline \multicolumn{8}{|l|}{ Fatigue } \\
\hline Null-Effect & -810.429 & 23 & 1.6309 & 1666.858 & 1771.307 & 1748.307 & 1675.391 \\
\hline Intercept-Only Effects & -803.631 & 27 & 1.5281 & 1661.263 & 1783.877 & 1756.877 & 1671.281 \\
\hline Linear Effects & -803.597 & 28 & 1.5247 & 1663.194 & 1790.349 & 1762.349 & 1673.582 \\
\hline All Effects & -802.322 & 29 & 1.4451 & 1662.644 & 1794.341 & 1765.341 & 1673.404 \\
\hline \multicolumn{8}{|l|}{ Learning } \\
\hline Null-Effect & -944.757 & 30 & 1.5026 & 1949.514 & 2085.752 & 2055.752 & 1960.644 \\
\hline Intercept-Only Effects & -938.356 & 34 & 1.3733 & 1944.712 & 2099.115 & 2065.115 & 1957.327 \\
\hline Linear Effects & -931.998 & 38 & 1.2455 & 1939.996 & 2112.564 & 2074.564 & 1954.095 \\
\hline All Effects & -931.155 & 44 & 1.1866 & 1950.310 & 2150.126 & 2106.126 & 1966.635 \\
\hline \multicolumn{8}{|l|}{ Satisfaction } \\
\hline Null-Effect & -804.504 & 30 & 1.3796 & 1669.008 & 1805.245 & 1775.245 & 1680.138 \\
\hline Intercept-Only Effects & -801.071 & 34 & 1.2543 & 1670.142 & 1804.545 & 1770.545 & 1682.757 \\
\hline Linear Effects & -800.373 & 38 & 1.2036 & 1676.746 & 1849.314 & 1811.314 & 1690.845 \\
\hline All Effects & -799.654 & 44 & 1.1177 & 1687.308 & 1887.123 & 1843.123 & 1703.633 \\
\hline \multicolumn{8}{|l|}{ Engagement } \\
\hline Null-Effect & -615.371 & 23 & 1.3952 & 1276.742 & 1381.191 & 1358.191 & 1285.275 \\
\hline Intercept-Only Effects & -598.768 & 27 & 1.7808 & 1251.536 & 1374.15 & 1347.150 & 1261.554 \\
\hline Linear Effects & -596.667 & 28 & 1.2404 & 1249.335 & 1376.490 & 1348.490 & 1259.723 \\
\hline All Effects & -594.922 & 29 & 1.2750 & 1247.844 & 1379.541 & 1350.541 & 1258.604 \\
\hline
\end{tabular}


Table 4

Effects of the Predictors on Motivation

\begin{tabular}{lcccc}
\hline & \multicolumn{2}{c}{ Autonomous: Intercept } & \multicolumn{2}{c}{ Controlled: Intercept } \\
Predictors & $b(\mathrm{SE})$ & $\beta$ & $b(\mathrm{SE})$ & $\beta$ \\
\hline Level 2: Occasion & & & & \\
Autonomy Support & $-.106(.845)$ & -.088 & $-.038(.164)$ & -.037 \\
Level 3: Person & & & & \\
Sex & $-.147(.251)$ & -.083 & $-.247(.119)^{*}$ & -.137 \\
Autonomy Support: Intercept & $1.736(.498)^{* *}$ & .570 & $-1.249(.561)^{*}$ & -.400 \\
\hline
\end{tabular}

Note. $* p<.05 ; * * p<.01 ; \mathrm{NA}=$ Not applicable; $b=$ Unstandardized regression coefficient; $\mathrm{SE}=$ Standard error; $\beta=$ Standardized regression coefficient (standardized at the participant or occasion level).

\section{Table 5}

Effects of Motivation on the Outcomes

\begin{tabular}{|c|c|c|c|c|c|c|c|c|c|}
\hline \multirow[b]{2}{*}{ Predictors } & \multicolumn{2}{|c|}{ Pos. Affect: Intercept } & \multicolumn{3}{|c|}{ Pos. Affect: Linear } & \multicolumn{4}{|c|}{ Fatigue: Intercept } \\
\hline & $b(\mathrm{SE})$ & $\beta$ & & (SE) & $\beta$ & $b(\mathrm{~S}$ & & $\beta$ & \\
\hline \multicolumn{10}{|l|}{ Level 2: Occasion } \\
\hline Autonomous & \multirow{3}{*}{$\begin{array}{l}.133(.153) \\
-.112(.143)\end{array}$} & .686 & \multicolumn{2}{|r|}{ NA } & NA & \multicolumn{2}{|c|}{$-.085(.130)$} & \multicolumn{2}{|c|}{-.062} \\
\hline Controlled & & -.492 & & NA & NA & \multicolumn{2}{|c|}{$.702(.292)^{*}$} & \multicolumn{2}{|c|}{.434} \\
\hline \multicolumn{9}{|l|}{ Level 3: Person } & \\
\hline Autonomous: Intercept & $.406(.074)^{* *}$ & .957 & \multicolumn{2}{|c|}{$.073(.032)^{*}$} & .612 & \multicolumn{2}{|c|}{$-.688(.272)^{*}$} & \multicolumn{2}{|c|}{-.188} \\
\hline Autonomous: Linear & $.210(.084)^{*}$ & .555 & \multicolumn{2}{|c|}{$.061(.069)$} & .579 & \multicolumn{2}{|c|}{ NA } & \multicolumn{2}{|c|}{ NA } \\
\hline \multirow[t]{3}{*}{ Controlled: Intercept } & $-.068(.062)$ & -164 & -.06 & $1(.039)$ & -.530 & $.173(.($ & $771)^{*}$ & .37 & \\
\hline & \multicolumn{2}{|c|}{ Learning: Intercept Le } & \multirow{2}{*}{\multicolumn{2}{|c|}{ Learning: Linear }} & \multicolumn{2}{|c|}{ Satis.: Intercept } & \multicolumn{3}{|c|}{ Eng.: Intercept } \\
\hline & $b(\mathrm{SE})$ & $\beta$ & & & $b(\mathrm{SE})$ & $\beta$ & $b$ & & $\beta$ \\
\hline \multicolumn{10}{|l|}{ Level 2: Occasion } \\
\hline Autonomous & $.307(.300)$ & .149 & NA & NA & $.023(.112)$ & .015 & .540 & 637) & .818 \\
\hline Controlled & $-.425(.874)$ & -.176 & NA & NA & $-.467(.541)$ & -.258 & 1.937 & & 2.505 \\
\hline \multicolumn{10}{|l|}{ Level 3: Person } \\
\hline Autonomous: Intercept & $1.066(.229)^{* *}$ & $1.421-.24$ & $(.151)$ & -.167 & $.146(.067)^{*}$ & $* .534$ & .398 & & .864 \\
\hline Autonomous: Linear & $.772(.196)^{* *}$ & $1.154-.23$ & $(.135)$ & -.186 & NA & NA & & & NA \\
\hline Controlled: Intercept & $-.032(.204)$ & $-.043-.05$ & $(.140)$ & -.040 & $-.066(.070)$ & ) -.250 & -.116 & 235) & -.257 \\
\hline
\end{tabular}




\section{Online Supplemental Materials for:}

\section{Nature, Predictor, and Outcomes of Motivation Trajectories during a Professional Training Program}

These online technical appendices are to be posted on the journal website and hot-linked to the manuscript. If the journal does not offer this possibility, these materials can alternatively be posted on one of our personal websites (we will adjust the in-text reference upon acceptance).

We would also be happy to have some of these materials brought back into the main manuscript, or included as published appendices if you deem it useful. We developed these materials to provide additional technical information and to keep the main manuscript from becoming needlessly long. 


\section{Table S1}

Regression Coefficients for the Effects of the Demographic Controls on Motivation

\begin{tabular}{lcccccccc}
\hline & \multicolumn{2}{c}{$\begin{array}{c}\text { Autonomous } \\
\text { (Intercept) }\end{array}$} & \multicolumn{2}{c}{$\begin{array}{c}\text { Autonomous } \\
\text { (Linear) }\end{array}$} & \multicolumn{2}{c}{$\begin{array}{c}\text { Autonomous } \\
\text { (Quadratic) }\end{array}$} & \multicolumn{2}{c}{$\begin{array}{c}\text { Controlled } \\
\text { (Intercept) }\end{array}$} \\
Demographic & $b(\mathrm{SE})$ & $\beta$ & $b(\mathrm{SE})$ & $\beta$ & $b(\mathrm{SE})$ & $\beta$ & $b(\mathrm{SE})$ & $\beta$ \\
\hline Sex & $.166(.313)$ & .094 & $-.477(.547)$ & -.241 & $.141(.143)$ & .291 & $-.826(.337) *$ & -.456 \\
Age & $.136(.178)$ & .157 & $-.015(.295)$ & -.015 & $-.005(.078)$ & -.020 & $.192(.13)$ & .216 \\
Education & $.193(.179)$ & .215 & $.473(.302)$ & .469 & $-.138(.08)$ & -.560 & $.261(.147)$ & .283 \\
Schedule & $-.255(.651)$ & -.101 & $-.247(1.053)$ & -.087 & $.094(.282)$ & .135 & $-.066(.324)$ & -.026 \\
Tenure & $-.017(.173)$ & -.020 & $-.195(.237)$ & -.196 & $.052(.061)$ & .211 & $-.149(.142)$ & -.163 \\
Manager & $-.127(.307)$ & -.072 & $.735(.516)$ & .371 & $-.205(.139)$ & -.421 & $.405(.258)$ & .224 \\
\hline Note.
\end{tabular}

Note. ${ }^{*} p<.05 ; * * p<.01 ; b=$ Unstandardized regression coefficient; $\mathrm{SE}=$ Standard error; $\beta=$

Standardized regression coefficient (standardized at the participant level); sex was coded 0 for males and 1 for females; age and education were coded in years; schedule was coded 0 for full-time and 1 for part-time; manager was coded 0 for manager and 1 for non-manager; education was coded 0 for no diploma, 1 for vocational training diploma, 2 for high school diploma, and 3 for University diploma. 


\section{Table S2}

Burst, Occasion, and Person-Specific Correlations

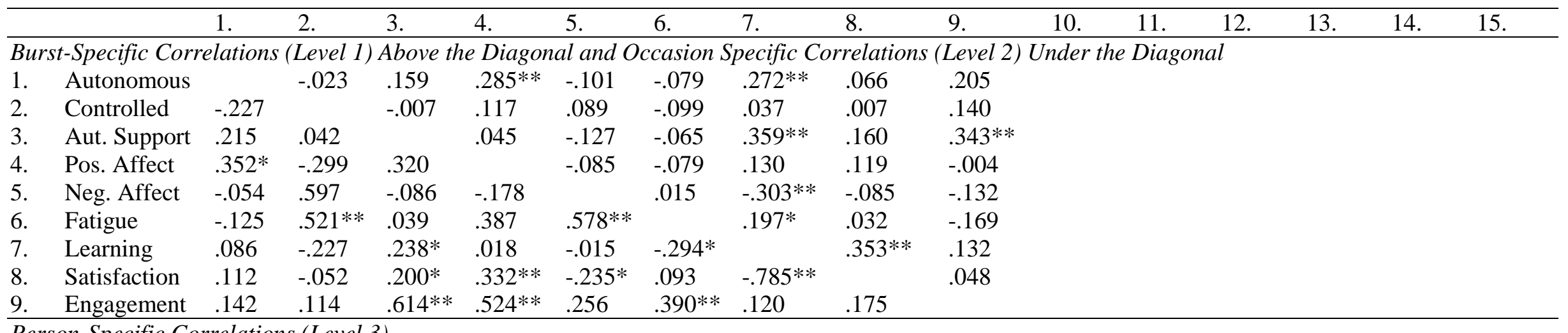

Person-Specific Correlations (Level 3)

\section{Autonomous}

2. Controlled $-.414^{*}$

3. Aut. Support $.718 *-.630 * *$

4. Pos. Affect $.798 * *-.407 * \quad .751 * *$

5. Neg. Affect $\quad-.278 \quad .319 \quad-.417 \quad-.461$

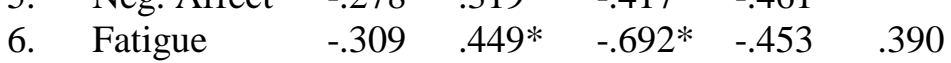

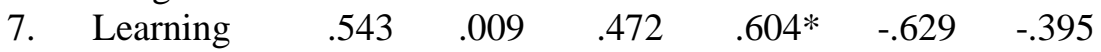

8. Satisfaction $\quad .654 \quad-.498 \quad .777 \quad \begin{array}{llllll}.554 & -.440 & -.590 & .478\end{array}$

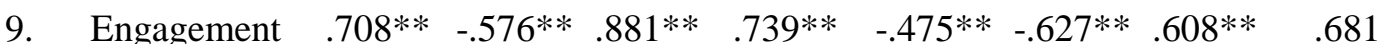

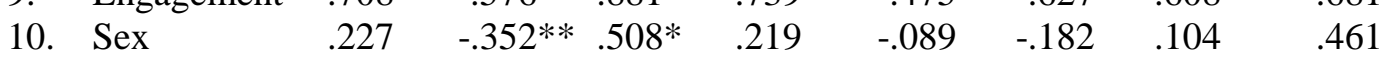

11. Age $\quad \begin{array}{llllllll}.030 & .105 & .103 & .101 & .236 & .015 & .095 & -.123\end{array}$

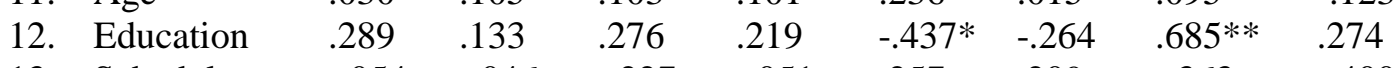

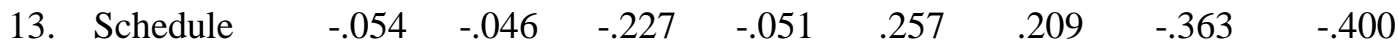

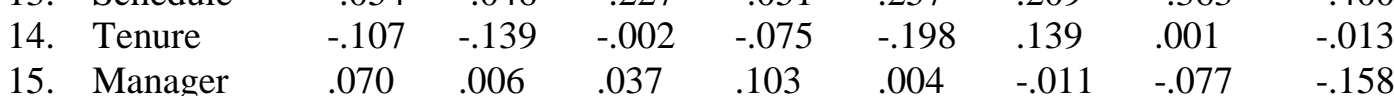

.070

Note. ${ }^{*} p<.05$; ** $p<.01$.

$\begin{array}{lllllll}.440 * * & & & & & \\ .029 & -.087 & & & & \\ .343 * * & .338 * & -.314 * & & & \\ -.095 & .212 & -.075 & -.068 & & \\ -.005 & -.015 & .240 & -.149 & -.221 & \\ .057 & .190 & -.154 & .033 & .172 & .048\end{array}$




\section{Table S3}

Model Fit Results from the Alternative Unconditional Growth Models

\begin{tabular}{|c|c|c|c|c|c|c|c|}
\hline Model & $\log \mathrm{L}$ & $\# \mathrm{fp}$ & $\mathrm{Sc}$ & AIC & CAIC & $\mathrm{BIC}$ & $\mathrm{ABIC}$ \\
\hline \multicolumn{8}{|c|}{ Autonomous Motivation } \\
\hline Intercept & -284.425 & 4 & 1.0270 & 576.851 & 595.016 & 591.016 & 578.335 \\
\hline Linear & -281.355 & 7 & .9913 & 576.709 & 608.498 & 601.498 & 579.307 \\
\hline Quadratic & -275.935 & 11 & .9974 & 573.870 & 623.824 & 612.824 & 577.952 \\
\hline \multicolumn{8}{|c|}{ Controlled Motivation } \\
\hline Intercept & -292.260 & 4 & 3.1959 & 592.520 & 610.638 & 606.638 & 593.957 \\
\hline Linear & -292.176 & 7 & 2.6700 & 598.352 & 630.058 & 623.058 & 600.867 \\
\hline Quadratic & -289.587 & 11 & 2.3115 & 601.174 & 650.998 & 639.998 & 605.126 \\
\hline \multicolumn{8}{|c|}{ Autonomy Support ${ }^{A}$} \\
\hline Intercept & -130.751 & 4 & 1.8159 & 269.501 & 287.112 & 283.112 & 270.435 \\
\hline Linear & -118.325 & 7 & 1.3298 & 250.649 & 281.468 & 274.468 & 252.285 \\
\hline \multicolumn{8}{|c|}{ Positive Affect } \\
\hline Intercept & -148.054 & 4 & 1.8318 & 304.109 & 322.274 & 318.274 & 305.593 \\
\hline Linear & -130.278 & 7 & 1.6216 & 274.555 & 306.344 & 299.344 & 277.153 \\
\hline Quadratic & -127.805 & 11 & 1.4167 & 277.610 & 327.564 & 316.564 & 281.691 \\
\hline \multicolumn{8}{|c|}{ Negative Affect } \\
\hline Intercept & -137.041 & 4 & 3.4317 & 282.083 & 300.200 & 296.200 & 283.520 \\
\hline Linear & -127.372 & 7 & 2.5102 & 268.743 & 300.449 & 293.449 & 271.258 \\
\hline Quadratic & -117.131 & 11 & 1.9193 & 256.262 & 306.085 & 295.085 & 260.214 \\
\hline \multicolumn{8}{|l|}{ Fatigue } \\
\hline Intercept & -248.466 & 4 & 2.5800 & 504.932 & 523.081 & 519.081 & 506.400 \\
\hline Linear & -246.164 & 7 & 1.9539 & 506.328 & 538.089 & 531.089 & 508.898 \\
\hline Quadratic & -243.805 & 11 & 1.7340 & 509.610 & 559.521 & 548.521 & 513.648 \\
\hline \multicolumn{8}{|l|}{ Learning } \\
\hline Intercept & -405.151 & 4 & 1.7962 & 818.302 & 836.451 & 832.451 & 819.770 \\
\hline Linear & -400.261 & 7 & 1.3796 & 814.521 & 846.283 & 839.283 & 817.091 \\
\hline Quadratic & -382.823 & 11 & 1.5888 & 787.646 & 837.556 & 826.556 & 791.684 \\
\hline \multicolumn{8}{|c|}{ Satisfaction } \\
\hline Intercept & -303.200 & 4 & 1.6146 & 614.400 & 632.550 & 628.550 & 615.869 \\
\hline Linear & -276.504 & 7 & 1.0469 & 567.008 & 598.769 & 591.769 & 569.577 \\
\hline Quadratic & -242.554 & 11 & 1.3766 & 507.108 & 557.019 & 546.019 & 511.147 \\
\hline \multicolumn{8}{|c|}{ Engagement $^{B}$} \\
\hline Intercept & -53.436 & 4 & 1.2257 & 114.871 & 131.222 & 127.222 & 114.559 \\
\hline
\end{tabular}

Note. $\log \mathrm{L}=$ Model loglikelihood; $\# \mathrm{fp}=$ Number of free parameters; $\mathrm{Sc}=$ Scaling correction factor for the maximum likelihood robust estimator; $\mathrm{AIC}=$ Akaïke information criterion; $\mathrm{CAIC}=\mathrm{Consistent}$ $\mathrm{AIC} ; \mathrm{BIC}=$ Bayesian information criterion; $\mathrm{ABIC}=$ Sample-size adjusted BIC $;{ }^{\mathrm{A}}$ Autonomy support perceptions were only assessed at three occasions (1-2-4), precluding the estimation of quadratic trajectories; ${ }^{B}$ Engagement was only assessed at two occasions (1-4), precluding the estimation of linear or quadratic trajectories. 


\section{Table S4}

Model Fit Results from the Alternative Conditional Growth Models

\begin{tabular}{|c|c|c|c|c|c|c|c|}
\hline Model & $\log \mathrm{L}$ & $\# \mathrm{fp}$ & Sc & AIC & CAIC & $\mathrm{BIC}$ & ABIC \\
\hline \multicolumn{8}{|l|}{ Autonomy Support } \\
\hline Null-Effect & -680.270 & 26 & 1.4035 & 1412.539 & 1530.612 & 1504.612 & 1422.186 \\
\hline Intercept-Only Effects & -666.919 & 32 & 1.5935 & 1397.837 & 1543.158 & 1511.158 & 1409.710 \\
\hline Linear Effects & -664.152 & 35 & 1.4850 & 1398.303 & 1557.247 & 1522.247 & 1411.289 \\
\hline All Effects & -661.806 & 40 & 1.4026 & 1403.612 & 1585.263 & 1545.263 & 1418.453 \\
\hline \multicolumn{8}{|l|}{ Positive Affect } \\
\hline Null-Effect & -692.220 & 26 & 1.4840 & 1436.441 & 1554.514 & 1528.514 & 1446.088 \\
\hline Intercept-Only Effects & -677.730 & 30 & 1.3918 & 1415.461 & 1551.699 & 1521.699 & 1426.591 \\
\hline Linear Effects & -671.312 & 34 & 1.3537 & 1410.624 & 1565.027 & 1531.027 & 1423.239 \\
\hline All Effects & -668.833 & 36 & 1.2637 & 1409.666 & 1573.152 & 1537.152 & 1423.023 \\
\hline \multicolumn{8}{|l|}{ Negative Affect } \\
\hline Null-Effect & -679.128 & 30 & 1.6167 & 1418.257 & 1554.495 & 1524.495 & 1429.388 \\
\hline Intercept-Only Effects & -675.816 & 34 & 1.5337 & 1419.631 & 1574.034 & 1540.034 & 1432.246 \\
\hline Linear Effects & -674.041 & 38 & 1.4951 & 1424.082 & 1596.65 & 1558.650 & 1438.181 \\
\hline All Effects & -670.438 & 44 & 1.3946 & 1428.876 & 1628.691 & 1584.691 & 1445.201 \\
\hline \multicolumn{8}{|l|}{ Fatigue } \\
\hline Null-Effect & -810.429 & 23 & 1.6309 & 1666.858 & 1771.307 & 1748.307 & 1675.391 \\
\hline Intercept-Only Effects & -803.631 & 27 & 1.5281 & 1661.263 & 1783.877 & 1756.877 & 1671.281 \\
\hline Linear Effects & -803.597 & 28 & 1.5247 & 1663.194 & 1790.349 & 1762.349 & 1673.582 \\
\hline All Effects & -802.322 & 29 & 1.4451 & 1662.644 & 1794.341 & 1765.341 & 1673.404 \\
\hline \multicolumn{8}{|l|}{ Learning } \\
\hline Null-Effect & -944.757 & 30 & 1.5026 & 1949.514 & 2085.752 & 2055.752 & 1960.644 \\
\hline Intercept-Only Effects & -938.356 & 34 & 1.3733 & 1944.712 & 2099.115 & 2065.115 & 1957.327 \\
\hline Linear Effects & -931.998 & 38 & 1.2455 & 1939.996 & 2112.564 & 2074.564 & 1954.095 \\
\hline All Effects & -931.155 & 44 & 1.1866 & 1950.310 & 2150.126 & 2106.126 & 1966.635 \\
\hline \multicolumn{8}{|l|}{ Satisfaction } \\
\hline Null-Effect & -804.504 & 30 & 1.3796 & 1669.008 & 1805.245 & 1775.245 & 1680.138 \\
\hline Intercept-Only Effects & -801.071 & 34 & 1.2543 & 1670.142 & 1804.545 & 1770.545 & 1682.757 \\
\hline Linear Effects & -800.373 & 38 & 1.2036 & 1676.746 & 1849.314 & 1811.314 & 1690.845 \\
\hline All Effects & -799.654 & 44 & 1.1177 & 1687.308 & 1887.123 & 1843.123 & 1703.633 \\
\hline \multicolumn{8}{|l|}{ Engagement } \\
\hline Null-Effect & -615.371 & 23 & 1.3952 & 1276.742 & 1381.191 & 1358.191 & 1285.275 \\
\hline Intercept-Only Effects & -598.768 & 27 & 1.7808 & 1251.536 & 1374.15 & 1347.150 & 1261.554 \\
\hline Linear Effects & -596.667 & 28 & 1.2404 & 1249.335 & 1376.490 & 1348.490 & 1259.723 \\
\hline All Effects & -594.922 & 29 & 1.2750 & 1247.844 & 1379.541 & 1350.541 & 1258.604 \\
\hline
\end{tabular}

